\title{
Complexation of C-Functionalized Cyclams with Copper(II) and Zinc(II): Similarities and Changes When Compared to Parent Cyclam Analogues.
}

Evan Lelong, ${ }^{\dagger}$ Jong-Min Suh, ${ }^{ \pm}$Gunhee Kim, ${ }^{ \pm}$David Esteban Gòmez, ${ }^{\perp}$ Marie Cordier $\tilde{,}$ Mi Hee Lim ${ }^{ \pm}$Rita Delgado, ${ }^{+}$Guy Royal, ${ }^{\ddagger}$ Carlos Platas-Iglesias, ${ }^{\perp, *}$ Hélène Bernard, ${ }^{\dagger}$ and Raphaël Tripier ${ }^{\dagger} *$

† Univ Brest, UMR CNRS 6521 CEMCA, 6 avenue Victor le Gorgeu, 29238 Brest, France. Email: raphael.tripier@univ-brest.fr

$\perp$ Departamento de Química, Facultade de Ciencias \& Centro de Investigaciones Científicas Avanzadas (CICA), Universidade da Coruña, 15071 A Coruña, Spain. Email: carlos.platas.iglesias@udc.es

+ Instituto de Tecnologia Química e Biológica António Xavier, Universidade Nova de Lisboa, Av. da República, 2780-157 Oeiras, Portugal. Email: delgado@itqb.unl.pt

‡Université Grenoble Alpes, CNRS, Département de Chimie Moléculaire (UMR5250), F38400 Grenoble, France. Email: guy.royal@univ-grenoble-alpes.fr

${ }^{ \pm}$Department of Chemistry, Korea Advanced Institute of Science and Technology (KAIST), Daejeon 34141, Republic of Korea. Email: miheelim@kaist.ac.kr

₹ Univ Rennes, CNRS, ISCR (Institut des Sciences Chimiques de Rennes) UMR 6226 ॥ F-35000 Rennes, France. Email: marie.dallon@univ-rennes1.fr

KEYWORDS. Cyclam; transition metal ions; configuration; $N$-methylation; $C$-functionalization.

\begin{abstract}
Herein, we report a comprehensive coordination study of the previously reported ligands cyclam, CB-cyclam TMC, DMC, CB-DMC, and of their C-functional analogues, cyclam-E, CB-cyclamE, TMC-E, DMC-E and CB-DMC-E. This group of ligands includes cyclam, cross-bridged cyclams, their di- or tetramethylated derivatives and the analogues bearing an additional hydroxyethyl group on one $\beta$ $\mathrm{N}$ position of the ring. These $\mathrm{Cu}(\mathrm{II})$ and $\mathrm{Zn}$ (II) complexes of these macrocycles have been highlighted previously for the biological interest, but the details of their structures in the solid state and in solution remained largely unexplored. In particular, we analyzed the impact that adding non-coordinating $N$ methyl and $C$-hydroxyethyl functionalities has in the structures of the complexes. All the $\mathrm{Cu}$ (II) and $\mathrm{Zn}$ (II) complexes were synthetized and investigated using single crystal X-ray diffraction and NMR, electronic absorption and EPR spectroscopies, along with DFT studies. Dissociation kinetics experiments in acidic conditions and an electrochemical study were also performed. A special attention was paid to analyze the different configurations present in solution and in the solid state, as well as the impact of the Cappended hydroxyethyl group on the coordination behavior. Various ratios of the trans-I, trans-III, and cis-V configurations have been observed depending on the degree of $\mathrm{N}$-methylation and the presence of the ethylene cross-bridge.
\end{abstract}

\section{INTRODUCTION}

Ligands composed of cyclam $(1,4,8,11$ tetraazacyclotetradecane), cyclen $(1,4,7,10$ tetrazacyclododecane), and tacn (1,4,7triazadodecane) are probably the most widely studied polyazamacrocyclic platforms for metal ion complexation, as they often form stable and inert chelates when suitably $\mathrm{N}$-functionalized. ${ }^{1,2}$ Transition metal ions belong to the large panel of cations that are efficiently chelated by these ligands, often when functionalized to offer six coordination sites. These chelates are widely used for several applications in medicine, ${ }^{1,3}$ catalysis and environmental sciences, ${ }^{4}$ depending on the nature of the central metal ion. Among the three macrocyclic backbones mentioned above, cyclam is the most adapted to the complexation of transition metals. ${ }^{5}$ In the absence of additional $\mathrm{N}$-functionalization, cyclam is better suited for the complexation of the small transition metal ions than the analogues with smaller ring sizes. ${ }^{6}$ Furthermore, the incorporation of pendant arms with additional donor groups often leads to complexes with very high thermodynamic stability and even inertness with respect to their dissociation. The high binding affinity of cyclam with transition metal ions is also associated with 
the various stable geometries that the complexes can adopt.

In 1965, Bosnich et al. described the six configurations that are likely to be formed upon coordination of cyclam to metal ions, particularly transition metals. ${ }^{7}$ They are denoted with the usual trans and cis terminology used for geometric isomers, depending on the relative position of the additional donor atoms that complete the metal coordination environment. Furthermore, different cis and trans isomers can be formed according to the orientation of the $\mathrm{N}-\mathrm{H}$ groups (or $\mathrm{N}-\mathrm{R} ; \mathrm{R}=$ alkyl group or function): trans-I, -II, -III and cis-V (trans-I when all point to the same side with respect to the mean macrocyclic plane; trans-III if they are pointing alternatively up and down, etc...). The orientation of the $\mathrm{N}-\mathrm{H}$ group depends on the absolute configuration of the nitrogen $(\mathrm{N})$ atom when its electron lone pair is engaged in a coordination with the metal center. Bosnich et al. and later Whimp et al. showed that the less constrained isomers are trans-I, trans-III, and cis-V. ${ }^{7,8}$ The trans-III configuration is more stable for an octahedral geometry, while trans-I is best suited for a square pyramidal geometry. The metal coordination sphere is then completed by additional groups introduced onto the macrocyclic $\mathrm{N}$-atoms (generally forming fivemembered chelating rings) or by anions or solvent molecules.

In 2003, Sadler et al. showed that the nature of the counterion has a drastic influence on the in the relative populations of the different configurations present in solution. ${ }^{9}$ Based on the diamagnetic character of $\mathrm{Zn}$ (II), an NMR study revealed the details of the solution equilibria involving the different configurations of $\left[\mathrm{Zn}(\mathbf{c y c l a m})(\mathrm{X})_{2}\right]$ complexes with various counterions. Three isomers, trans-I, trans-III, and cis-V, were identified by NMR with a different ratio depending on the counterion. In addition, solid-state studies provided valuable information on the geometries of the cyclam complexes. With a few exceptions, the crystallographic structures of metal complexes with cyclam evidence trans-III configurations. ${ }^{9-13}$

Regardless the targeted application, understanding the structures of cyclam complexes is of extraordinary importance to explain their behavior and design complexes with specific properties. For instance, tetramethylcyclam (TMC in this manuscript) and especially its metal complexes $[\mathrm{M}(\mathbf{T M C})]^{2+}[\mathrm{M}=$ $\mathrm{Cu}(\mathrm{II}), \mathrm{Zn}(\mathrm{II}), \mathrm{Co}(\mathrm{II})$, and $\mathrm{Ni}(\mathrm{II})]$, have been studied by some of us for their interaction with amyloid- $\beta$, a peptide associated with Alzheimer disease. ${ }^{14}$ This $N$-methylated cyclam derivative was selected to generate metal complexes with an incomplete coordination sphere, thereby allowing amino acid residues and a hydroxide ion to interact with the metal center. The study showed that the mechanism responsible for hydrolytic cleavage of amyloid- $\beta$ involves the formation of a-hydroxo complex $[\mathrm{M}(\mathrm{TMC})(\mathrm{OH})]^{+}$, whose formation depends of the geometry of the complexes and the properties of the ligand. The TMC complexes mainly adopt the trans-I configuration. ${ }^{14-18}$ A previous study, however, revealed a trans-III configuration for [Cu(TMC) $\left.\left(\mathrm{NO}_{3}\right)_{2}\right]$, demonstrating the influence of the counterions on the structure of the complex in the solid state. ${ }^{19}$

Recently, we explored the ability of cyclam and CB-cyclam, and several $\mathrm{N}$-methylated cyclam derivatives (TMC, DMC, CB-DMC) to interact with amyloid- $\beta$ upon formation $\mathrm{Cu}$ (II) and $\mathrm{Zn}$ (II) complexes (Chart 1). ${ }^{20}$ DMC stands for $\mathrm{N}_{1}, \mathrm{~N}_{8}$ dimethylcyclam, ${ }^{21}$ while the "CB" acronym denotes the "cross-bridged" version of cyclam, meaning that an ethylene moiety is connecting two opposite $\mathrm{N}$ atoms. ${ }^{22,23}$ The constrained structure of the ligand forces a cis- $\mathrm{V}$ configuration to the resulting complexes. ${ }^{24-26}$ In the same paper, the previous series was compared to the analogues bearing a $C$-appended hydroxyethyl group on one of the $\beta-N$ positions of the ring: cyclam-E, CB-cyclam-E, TMC-E, DMC-E and CB-DMC-E (Chart 1). The C-functionalization strategy was developed to provide a second functionality to the macrocycle, different from the one introduced with $\mathrm{N}$-chelating units. ${ }^{27}$ We and others have largely contributed to this chemistry using these derivatives for several applications, especially for the conjugation of the macrocycles to an external support or a targeting moiety. ${ }^{28-31}$ The structural modifications introduced through $C$-functionalization of the cyclam framework affect the biological properties of the complexes by modifying the lipophilic character of the ligands as well as by directing the complex to the desired target in vivo.

What is the actual influence of $C$ functionalization on the properties of the metal complex? Limited information has been reported in literature ${ }^{27,30,32-35}$ since the first examples of $C$ functionalized cyclam derivatives reported by Tabushi et al. in $1977 .{ }^{36}$ It has been noted that the introduction of $C$-appended groups, when not engaged directly in the coordination sphere, does not drastically change the thermodynamic stability of complexes of cyclam derivatives with transition metal ions. ${ }^{20,30,31,37-39}$ However, the impact that $C$-functionalization has in the structure of the complexes remains unexplored. Does it affect the configurations present in solution and will complexes still preserve their overall properties? 


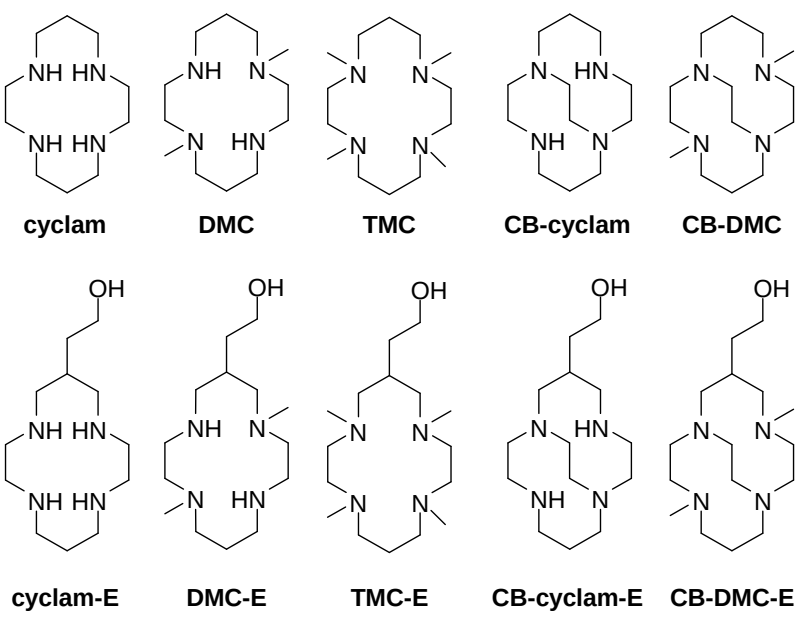

CHART 1. Structures of cyclam derivatives: cyclam, 1,4,8,11-tetraazacyclotetradecane; DMC, 1,8-dimethyl-1,4,8,11tetraazacyclotetradecane; TMC, 1,4,8,11tetramethyl-1,4,8,11-tetraazacyclotetradecane; CB-cyclam, tetraazabicyclo[6.6.2] hexadecane: CB-DMC 4,11-dimethyl-1,4,8,11-

tetraazabicyclo[6.6.2] hexadecane; cyclam-E, 2$(1,4,8,11$-tetraazacyclotetradec-6-yl)ethanol;

DMC-E,

2-(1,8-dimethyl-1,4,8,11tetraazacyclotetradec-6-yl)ethanol; TMC-E, 2$(1,4,8,11$-tetramethyl-1,4,8,11-

tetraazacyclotetradec-6-yl)ethanol; CB-cyclamE, 2-(1,4,8,11-tetraazabicyclo[6.6.2] hexadec-6yl)ethanol; CB-DMC-E, 2-(4,11-dimethyl-1,4,8,11tetraazabicyclo[6.6.2] hexadec-6-yl)ethanol.

To address the questions introduced above, herein we report the coordination properties of the $\mathrm{Cu}(\mathrm{II})$ and $\mathrm{Zn}(\mathrm{II})$ complexes of cyclam, CBcyclam TMC, DMC, CB-DMC, and their Cfunctionalized analogues cyclam-E, CB-cyclamE, TMC-E, DMC-E and CB-DMC-E. The presence of a different number of $N$-methyl substituents in this series of ligands is expected to affect the populations of the different configurations present in solution, while keeping the overall denticity of the ligands constant. A detailed understanding of the structure of the complexes was obtained using a combination of X-ray diffraction measurements, electronic absorption, EPR and NMR spectroscopies, electrochemistry investigations and DFT calculations. The comparison of our results with the scattered data reported in the literature (especially for the non$C$-functionalized compounds) revealed the details of the structures of these complexes at the molecular level both in the solid state and in solution. Furthermore, we also analyzed the effect of the counter ion used in the complexation reaction.

\section{RESULTS AND DISCUSSION}

Syntheses of the ligands and complexes
All the ligands presented in this paper were synthesized as previously described in the literature. ${ }^{20-23,27}$ Among them, the $C$-functionalized constrained cyclam derivatives have a structural interest because of the two potentially different relative positions of the ethylene cross-bridge and the $C$-appended hydroxyethyl pendant. During the synthesis, CB-cyclam-E and CB-DMC-E provided a mixture of two syn and anti diastereoisomers as previously observed in our previous investigations. ${ }^{40}$ Crystals suitable for Xray diffraction experiments, obtained from a solution containing a mixture of the two isomers, evidence the presence of both isomers (see Figure S3 and Table S1) in the crystal lattice. Furthermore, the diastereoisomers of CB-DMC-E were purified by chromatography (see ${ }^{1} \mathrm{H}$ and ${ }^{13} \mathrm{C}$ NMR spectra, Figures S1 and S2).

The syntheses of $\mathrm{Cu}(\mathrm{II})$ and $\mathrm{Zn}$ (II) complexes of all ligands were undertaken. The series of "original" cyclam ligands and their $C$ functionalized derivatives, namely $M(\text { cyclam })^{2+}$, $M(D M C)^{2+}, M(T M C)^{2+}, M(\text { cyclam-E })^{2+}, M(D M C-$ $\mathbf{E})^{2+}, \mathrm{M}(\mathbf{T M C}-\mathbf{E})^{2+}$ complexes $(\mathrm{M}=\mathrm{Cu}$ and $\mathrm{Zn})$, were prepared in water at $80{ }^{\circ} \mathrm{C}$. These conditions ensure the complete formation of the expected complexes, in spite of fast complexation in some cases. The constrained cyclam complexes, $\mathrm{M}(\mathbf{C B}-\mathbf{c y c l a m})^{2+}, \mathrm{M}(\mathbf{C B}-\mathbf{c y c l a m}-\mathbf{E})^{2+}$, $\mathrm{M}(\mathbf{C B}-\mathbf{D M C})^{2+}$ and $\mathrm{M}(\mathbf{C B}-\mathbf{D M C}-\mathbf{E})^{2+}(\mathbf{M}=\mathrm{Cu}, \mathrm{Zn}$, and $\mathrm{Co}$ ), required more drastic conditions, and were synthesized in refluxing water while maintaining the $\mathrm{pH}$ at 7-8. All compounds were characterized by HRMS, as described in Figures S4-S23.

\section{Solid-state characterization}

Cyclam and cyclam-E complexes where already discussed in the literature by Paoletti and coll. ${ }^{41}$ and some of us. $^{27}$ The structures of $\left[\mathrm{Cu}(\mathbf{c y c l a m})\left(\mathrm{ClO}_{4}\right)_{2}\right]$ and [Cu(cyclam-E $\left.)\left(\mathrm{ClO}_{4}\right)_{2}\right]$ are replotted in Figure $\mathrm{S} 24$ to facilitate the discussion. For both complexes, the X-ray structures reveal a trans-III configuration and a distorted octahedral coordination geometry. The X-ray structures of $\mathrm{Cu}$ (II) and $\mathrm{Zn}$ (II) complexes with DMC where previously published by some of us. ${ }^{20}$ The structure of the $\left[\mathrm{Cu}(\mathrm{DMC})(\mathrm{Cl})_{2}\right]$ entity (presented in Figure S25) evidences a trans-III conformation. $^{3}$ The metal ion is directly coordinated to the four $\mathrm{N}$-atoms of the macrocyclic unit, with $\mathrm{Cu}(1)-\mathrm{N}(2)$ distances similar to those observed for [Cu(cyclam $\left.)\left(\mathrm{ClO}_{4}\right)_{2}\right]$. The four $\mathrm{N}$ atoms of the ligand and the metal ion are co-planar. The secondary amines provide stronger coordination to the metal center than the tertiary amines: $\mathrm{Cu}-\mathrm{N}(2)=2.002 \AA<\mathrm{Cu}-\mathrm{N}(1)$ $=2.100 \AA$. The metal ion in $\left[\mathrm{Zn}(\mathbf{D M C})(\mathrm{Cl})_{2}\right]$ displays a distorted octahedral geometry with the ligand in the cis-V conformation. The bond lengths between the secondary amines and the 
$\mathrm{Zn}(\mathrm{II})$ center are shorter than those involving tertiary amines $(\mathrm{Zn}-\mathrm{N}(2)=2.110 \AA<\mathrm{Zn}-\mathrm{N}(1)=$ $2.268 \AA$ ).

Unfortunately, we could not obtain single crystals of the DMC-E complexes with the targeted metal ions with sufficient quality. Single crystals of $\left[\mathrm{Cu}(\mathbf{D M C}-\mathbf{E}) \mathrm{Cl} \mathrm{NO}_{3}\right.$ were isolated by diffusion of $\mathrm{Et}_{2} \mathrm{O}$ in a solution of the complex in $\mathrm{CH}_{3} \mathrm{CN}$, leading to a structure with a quite low resolution. Nevertheless, the data showed that the complex crystallizes as dinuclear entities bridged by chloride anions. The $[\mathrm{Cu}(\mathbf{D M C}-\mathbf{E})]^{2+}$ units adopt a type-I conformation with $\mathrm{Cu}-\mathrm{N}$ distances in the range 2.96-2.10 $\AA$. We prefer to denote this conformation as type-I rather than trans-I, as the presence of a single additional donor atom (a chloride anion) does not allow defining cis and trans isomers. The six-membered chelate rings adopt chair conformations with the hydroxyethyl substituent at the equatorial position (Figure 1 and X-ray crystallographic data in Table S2).

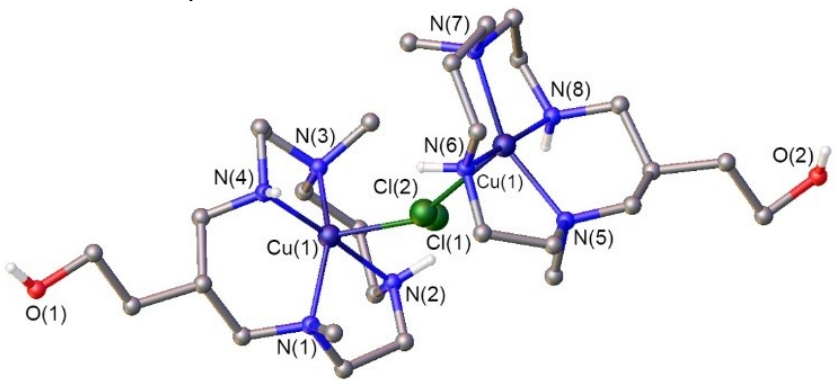

Figure 1. View of the crystal structure of [Cu(DMCE) Cl] $\mathrm{NO}_{3}$. The nitrate anions were omitted for simplicity.

The structures of the complexes with $C$ functionalized TMC were obtained from the complexes synthesized with nitrate salts and nitric acid in water. Both present a chloride ion coordinated to the metal center, probably coming from inorganic salts present in the batch of the ligand used for complexation. The structures of the complex cations present in [CU(TMC-E)Cl] $\left(\mathrm{NO}_{3}\right)$ and $[\mathrm{Zn}(\mathrm{TMC}-\mathrm{E}) \mathrm{Cl}]\left(\mathrm{NO}_{3}\right)$ are shown in Figure 2, while selected lengths and angles are given in Table 1 (additional data in Tables S3 and S4).

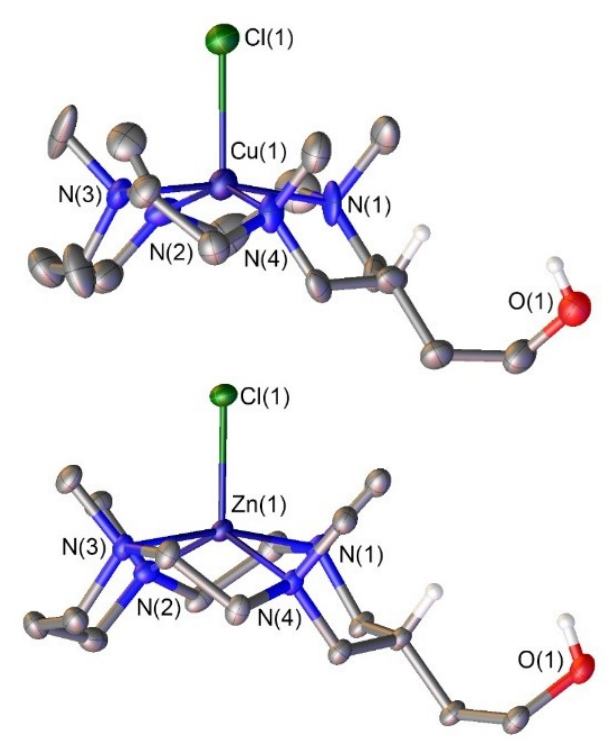

Figure 2. ORTEP diagrams of the crystal structures of $[\mathrm{Cu}(\mathrm{TMC}-\mathrm{E}) \mathrm{Cl}] \mathrm{NO}_{3}$ and $[\mathrm{Zn}(\mathrm{TMC}-\mathrm{E}) \mathrm{Cl}] \mathrm{NO}_{3}$ plotted at $30 \%$ of ellipsoids probability.

As for their non-C-functionalized analogues reported in the literature, ${ }^{15-18}$ these complexes exhibit a type-I configuration, with the $\mathrm{N}-\mathrm{CH}_{3}$ groups pointing to the same side of the macrocyclic unit (the presence of a single additional ligand. The ORTEP views also show that the 6-membered chelates adopt chair configurations, with the $C$-pendant functions at the equatorial position. The metal ions in the two complexes have a coordination number of five and square pyramidal coordination geometries with distorted square bases. Indeed, the four N atoms of the $\mathrm{Cu}(\mathrm{II})$ and $\mathrm{Zn}$ (II) complexes define dihedral angles of $9.7^{\circ}$ and $19.6^{\circ}$, respectively. Due to its slightly larger ionic radius, the $\mathrm{Zn}$ (II) ion is located at a longer distance of $0.54 \AA$ from the least-squares plane defined by the four $\mathrm{N}$ atoms than $\mathrm{Cu}(\mathrm{II})(0.37 \AA)$. These values are slightly longer than those reported in the literature for $[\mathrm{Zn}(\mathbf{T M C}) \mathrm{Cl}]^{+}(0.43 \AA)$ and $[\mathrm{Cu}(\mathrm{TMC}) \mathrm{NCS}]^{2+}(0.24 \AA) .{ }^{16,17}$ The bond angles involving adjacent donor atoms of the basal plane are relatively close to the ideal value of 90 o expected for a square pyramid (Table 1 ).

Table 1. Selected bond lengths $(\AA)$ and angles $\left({ }^{\circ}\right)$ for $[\mathrm{Cu}(\mathbf{T M C}-\mathrm{E}) \mathrm{Cl}] \mathrm{NO}_{3}, \quad[\mathrm{Zn}(\mathbf{T M C}-\mathrm{E}) \mathrm{Cl}] \mathrm{NO}_{3}, \quad[\mathrm{Zn}(\mathbf{C B}-\mathbf{c y c l a m}-$ E)Cl]Cl.

\begin{tabular}{llll}
\hline & Cu / TMC-E & Zn / TMC-E & $\begin{array}{l}\text { Zn / CB- } \\
\text { cyclam-E }\end{array}$ \\
\hline $\mathrm{M}(1)-\mathrm{N}(1)$ & $2.198(3)$ & $2.239(3)$ & $2.098(2)$ \\
$\mathrm{M}(1)-\mathrm{N}(2)$ & $2.093(2)$ & $2.149(3)$ & $2.149(3)$ \\
$\mathrm{M}(1)-\mathrm{N}(3)$ & $2.121(2)$ & $2.253(3)$ & $2.253(3)$ \\
$\mathrm{M}(1)-\mathrm{N}(4)$ & $1.954(3)$ & $2.132(3)$ & $2.132(3)$ \\
$\mathrm{M}(1)-\mathrm{Cl}(1)$ & $2.483(2)$ & & $2.284(8) /$ \\
$\mathrm{N}(1)-\mathrm{M}(1)-\mathrm{N}(2)$ & $88.1(6)$ & $84.0(1)$ & $2.6155(7)$ \\
$\mathrm{N}(2)-\mathrm{M}(1)-\mathrm{N}(3)$ & $91.5(4)$ & $90.4(1)$ & $82.79(8)$ \\
& & &
\end{tabular}


$\mathrm{N}(3)-\mathrm{M}(1)-\mathrm{N}(4)$

$\mathrm{N}(4)-\mathrm{M}(1)-\mathrm{N}(1)$

A comparison of the X-ray structures of the $\mathrm{Cu}(\mathrm{II})$ and $\mathrm{Zn}$ (II) complexes of TMC-E with those reported in the literature for the TMC analogues, ${ }^{16,17}$ shows that they are quite similar (Figure S26). The structures of [Cu(TMC)NCS] ${ }^{+}$ and $[\mathrm{Cu}(\mathbf{T M C}-\mathbf{E}) \mathrm{Cl}]^{+}$complexes overlap almost perfectly. The superposition of the $[\mathrm{Zn}(\mathbf{T M C}) \mathrm{Cl}]^{+}$ and $[\mathrm{Zn}(\mathbf{T M C}-\mathbf{E}) \mathrm{Cl}]^{+}$complexes evidences more pronounced differences in the structures, which arise from different configuration of the fivemembered chelate rings. Indeed, the two fivemembered rings in $[\mathrm{Zn}(\mathbf{T M C}-\mathbf{E}) \mathrm{Cl}]^{+}$adopt identical configurations, which can be denoted as

$(\delta \delta)$ or $(\lambda \lambda),{ }^{42}$ as the two enantiomers are present in the crystal lattice related by an inversion center. A similar situation holds for the $\mathrm{Cu}$ analogue. The $\left[\mathrm{Zn}(\mathbf{T M C}) \mathrm{Cl}^{+}\right.$complex, however, presents a $(\delta \lambda)$ configuration of the fivemembered rings, resulting in the presence of a mirror plane bisecting the TMC unit, which is therefore achiral. In spite of the different macrocyclic conformations, the positions of the four $\mathrm{N}$ atoms, a chloride anion, and the metal center remain very close in $[\mathrm{Zn}(\mathbf{T M C}-\mathbf{E}) \mathrm{Cl}]^{+}$and $[\mathrm{Zn}(\mathbf{T M C}) \mathrm{Cl}]^{+}$, indicating that $C$-functionalization of the macrocycle does not alter significantly its coordination ability.

Among the C-functionalized "cross-bridged" cyclam complexes, only crystals of [ $\mathrm{Zn}(\mathbf{C B}-$ cyclam-E) $\mathrm{Cl}_{2}$ ] suitable for $X$-ray diffraction could be obtained. The structure revealed the presence of two diastereomers, syn and anti (Figure 3), as observed for the free ligand. These diastereoisomers differ in the relative orientation of the hydroxyethyl substituent and the ethylene bridge connecting the $\mathrm{N}(2)$ and $\mathrm{N}(3)$ atoms. Two centrosymmetrically related $[\mathrm{Zn}(\mathbf{C B}-\mathbf{c y c l a m - E})]^{2+}$ units are joined by two bridging chloride ligands, affording a distorted octahedral geometry. The two diastereomers differ in the absolute configuration of the asymmetric carbon, either $R$ or $S$ (underlined), and the configuration of the four $\mathrm{N}$ atoms of the macrocyclic entity. Each centrosymmetrically related [(ZnCB-cyclamE $\left.)_{2}(\mu-C l)_{2}\right]^{2+}$ entity contains the anti-S, $S, S, S, S /$ anti- $\underline{R}, R, R, R, R$ and syn- $\underline{R}, S, S, S, S /$ syn- $\underline{S}, R, R, R, R$ enantiomeric pairs, which were modelled as disordered entities with similar occupation factors. The six-membered chelate carrying the $C$-function adopts a chair conformation in the anti-isomer, and a twist-boat conformation in the syn-isomer. These conformations are likely imposed to allow an equatorial position of the substituent instead of the more sterically demanding axial orientation. The two diastereoisomers are characterized by identical, crystallographically imposed, bond distances and angles of the metal coordination environment. The $\mathrm{Zn}-\mathrm{N}$ distances involving secondary amine $\mathrm{N}$ atoms are slightly shorter than those involving the tertiary $\mathrm{N}$ atoms (Table 1 ). The $\mathrm{Zn}(\mathrm{II})$ center exhibits distorted octahedral coordination. Regarding bond distances, the structure of the $C$-functionalized $\quad\left[(Z n C B-c y c l a m-E)_{2}(u-C l)_{2}\right]^{2+}$ complex is very similar to the structure reported for the non-C-functionalized analogue. ${ }^{24,43} \mathrm{~A}$ superposition of the structures of [(ZnCBcyclam-E $\left.)_{2}(\mu-\mathrm{Cl})_{2}\right]^{2+}$ and [(ZnCBcyclam $\left.)_{2}(\mu-\mathrm{Cl})_{2}\right]^{2+}$ (Figure S27) evidences a very similar macrocyclic conformation of the latter and the anti isomer of the former, while the syn isomer shows a clearly different structure associated to the twist-boat conformation of one of the six-membered chelate rings. These results suggest that the anti isomer leads to a more stable structure.
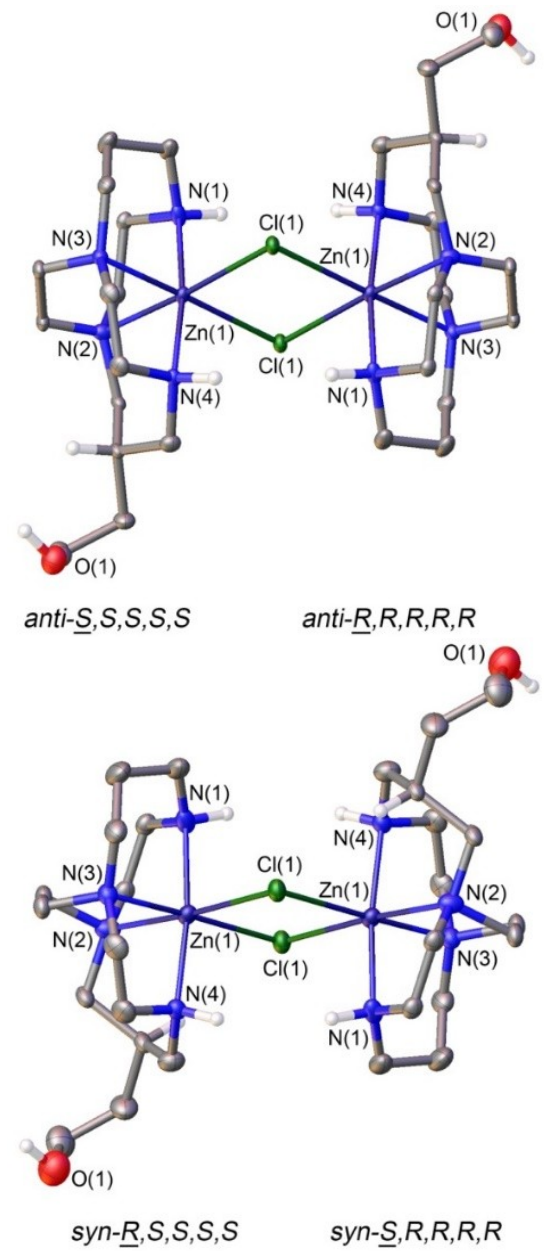

Figure 3. ORTEP views of [(ZnCB-cyclam$\left.\mathbf{E})_{2}(\mu-\mathrm{Cl})_{2}\right]^{2+}$ in anti and syn configurations. Counter ions and hydrogen atoms are omitted for clarity, except those carried by the nitrogen atoms and asymmetric carbon. Ellipsoids are drawn at $50 \%$ probability.

\section{Solution investigation}

NMR studies on $\mathrm{Zn}(\mathrm{L}) \mathrm{Cl}_{2}$ complexes. NMR studies of the $\mathrm{Zn}$ (II) complexes of cyclam and 
cyclam-E derivatives were performed to identify the different configurations present in solution. We took advantage of the seminal studies published by Sadler et al. on Zn(cyclam $)^{2+}$ for spectral attribution. ${ }^{9}$ The ${ }^{1} \mathrm{H}$ and ${ }^{13} \mathrm{C}$ NMR studies carried out on $\mathrm{Zn}$ (cyclam) $\mathrm{Cl}_{2}$ (Figure 28) provided results very close to those reported previously using the chloride salt. Due to superimposed signals, the ${ }^{1} \mathrm{H}$ NMR spectrum was quite difficult to integrate in order to obtain the different isomers ratios. Thus, an integration of the characteristic signals of the secondary carbon atoms in the $\beta$ position with respect to the $\mathrm{N}$ atoms $\left(\beta-\mathrm{CH}_{2}-\mathrm{N}\right)$ was carried out on the ${ }^{13} \mathrm{C} \mathrm{Jmod}$ NMR spectrum. This integration must be considered with caution; it is indeed imperative to compare signals from carbon atoms of the same nature, as the relaxation time and the nuclear Overhauser effect (NOE) induced by the Jmod sequence is expected to affect the intensity of the signals. ${ }^{44}$ In the case of $\mathrm{Zn}$ (cyclam) $\mathrm{Cl}_{2}$, the integration of these signals gave results equivalent to those obtained by Sadler by integrating the ${ }^{1} \mathrm{H}$ NMR signals (Table 2). The nature of the counter ion considerably affects the isomer populations and thus subsequent NMR studies were conducted employing the $\mathrm{Zn}(\mathbf{L}) \mathrm{Cl}_{2}$ complexes.

Table 2. Relative populations of the different isomers in $\mathrm{Zn}(\mathbf{L}) \mathrm{Cl}_{2}$ as estimated from NMR spectroscopy.

\begin{tabular}{llll}
\hline & trans-I & trans-III & cis-V \\
\hline $\begin{array}{l}\text { Zn(cyclam) } \mathrm{Cl}_{2} \\
a\end{array}$ & 11 & 82 & 7 \\
$\mathrm{Zn}($ cyclam- & 12 & 68 & 20 \\
$\mathbf{E}) \mathrm{Cl}_{2}$ & & 9 & 44 \\
$\mathrm{Zn}(\mathbf{D M C}) \mathrm{Cl}_{2}$ & 47 & 13 & 49 \\
$\mathrm{Zn}(\mathbf{D M C}-\mathrm{E}) \mathrm{Cl}_{2}$ & 38 & & \\
$\mathrm{Zn}(\mathbf{T M C}) \mathrm{Cl}_{2}$ & 100 & & \\
$\mathrm{Zn}(\mathbf{T M C}-\mathrm{E}) \mathrm{Cl}_{2}$ & 100 & &
\end{tabular}

${ }^{a}$ Sadler reported the abundances of 11,80 and 9\% for the trans-I, trans-III and $c i s$-V isomers, respectively, using the chloride salt. ${ }^{9}$

The $C$-functionalized analogue $\mathrm{Zn}$ (cyclam-E) $\mathrm{Cl}_{2}$ was then studied to investigate whether the functional group at $\beta$ position with respect to the amine $\mathrm{N}$ atoms has the influence in the population of the different isomers. The ${ }^{1} \mathrm{H}$, Jmod${ }^{13} \mathrm{C}$, HMBC, HMQC, and ${ }^{1} \mathrm{H},{ }^{1} \mathrm{H}$-COSY spectra allowed us to attribute the signals of different isomers. By analogy with [ $\left.\mathrm{Zn}(\mathbf{c y c l a m}) \mathrm{Cl}_{2}\right]$, the major species was considered to be the trans-III configuration. The cis-V configuration was then identified based on the important differences of the chemical shifts compared to the previous one.
This species is geometrically very different compared with the trans-III and trans-I isomers because of the large torsion angle of the four $\mathrm{N}$ atoms, which drastically affects the ${ }^{1} \mathrm{H}$ chemical shifts: $4.3 \mathrm{ppm}$ for $\beta-\mathrm{CH}_{2} \mathrm{OH}$ (in pink, Figure S29) and $2.1 \mathrm{ppm}$ for $\beta-\mathrm{CH}-\mathrm{N}$ (Figure S29). Again, integrating the ${ }^{1} \mathrm{H}$ spectrum was relatively complex due to partial overlaps of several signals, but it allowed the quantification of the cis- $\mathrm{V}$ configuration, which appears to be approximately $20 \%$. The proportions of trans-III and trans-I species could not be determined from the ${ }^{1} \mathrm{H}$ NMR spectrum. The integration of characteristic signals on the ${ }^{13} \mathrm{C}$ NMR spectrum indicates a cis- $\mathrm{V}$ configuration ratio between 17 and $23 \%$, which remains very close to the value calculated with ${ }^{1} \mathrm{H}$ NMR. Only the signal of the $\beta$ $\mathrm{CH}-\mathrm{N}$ carbon atom (in light green) allows the distinction of the trans-III and trans-I configurations. Based on the integration of this signal for the three configurations, the trans-III, trans-I and cis-V populations are approximately $68 \%, 12 \%$ and $20 \%$, respectively (Table 2 ). The presence of the $C$-appended functionality on the cyclam backbone influences the distribution of the various isomers present in solution. The proportion of cis- $\mathrm{V}$ increases at the expense of trans-III, while the relative amount of the trans-I configuration remains unchanged. Thus, the hydroxyethyl chain appears to have a certain steric impact that affects slightly the population of the different isomers.

The dimethyl derivatives were studied following to the same approach. The NMR spectra recorded for $\mathrm{Zn}(\mathrm{DMC}) \mathrm{Cl}_{2}$ revealed the presence of three isomers in equilibrium $\left({ }^{13} \mathrm{C}\right.$ NMR spectrum in Figure S30). Once again, due to signal overlap, the ${ }^{1} \mathrm{H}$ NMR spectra did not allow the determination of the population of each isomer (Figure S30). To take advantage of ${ }^{13} \mathrm{C}$ NMR spectroscopy, acquisition was performed using a long $d_{1}(15 s)$ to ensure that all nuclei have returned to equilibrium before starting a new sequence. The isomers were mainly assigned through the chemical shifts of methyl groups, which for the cis-V configurations are usually more deshielded (> $48 \mathrm{ppm}$ ) than for the other isomers. For $\mathrm{Zn}(\mathbf{D M C}) \mathrm{Cl}_{2}$, the methyl group resonance at $48.4 \mathrm{ppm}$ was attributed to the cis-V configuration. DFT calculations performed on $[\mathrm{Zn}(\mathbf{D M C}) \mathrm{Cl}]^{+}$predict a ${ }^{13} \mathrm{C}$ chemical shift of 49.8 ppm for the methyl protons of the cis- $\mathrm{V}$ isomer, in good agreement with the experimental value. The corresponding values calculated for the trans-I and trans-III isomers are $\delta=44.1$ and $42.6 \mathrm{ppm}$. Thus, the signals observed in the ${ }^{13} \mathrm{C}$ NMR spectrum at 44.8 and $42.8 \mathrm{ppm}$ were assigned to the trans-I and trans-III isomers, respectively. The ratio of each isomer was calculated from the integration of the characteristic signal of $\beta-\mathrm{CH}_{2}-\mathrm{N}$ carbon atoms. In $\mathrm{Zn}(\mathbf{D M C}) \mathrm{Cl}_{2}$, a mixture of the trans-III, trans-I, and cis-V configurations with 
respective populations of about $9 \%, 47 \%$ and 44 $\%$ was found in solution.

The addition of two methyl groups on the $\mathrm{N}$ atoms of cyclam stabilizes the cis- $\mathrm{V}$ and trans-I configurations, which have very similar populations (44\% and $47 \%$, respectively). The trans-III isomer, with about $9 \%$ ratio, is the less abundant among the three observed in solution. These results are in line with the solid-state study, as the crystallographic structure of the complex showed a cis-V configuration, which is thermodynamically as stable as the trans-I one. The $\mathrm{Zn}(\mathbf{D M C}-\mathbf{E}) \mathrm{Cl}_{2}$ complex showed the same behavior in solution with the presence of three configurations, two of them largely predominating (Figure S31). The assignment of the configurations was made according to the same features: the signals of methyl groups shifted to lower fields (48.6 and $48.5 \mathrm{ppm}$ ) were attributed to the cis-V species. The second series of peaks likely corresponds to the trans-I isomer, while the minor species is assigned to the trans-l isomer. The ${ }^{13} \mathrm{C}$ NMR signals due to the $\mathrm{CH}_{3}, \beta-\mathrm{CH}_{2}-\mathrm{OH}, \beta$ $\mathrm{CH}-\mathrm{N}$ and $\mathrm{\beta}-\mathrm{CH}_{2}-\mathrm{N}$ nuclei were used as probes to assign the species present in solution and their respective abundances (using an average of the different values obtained for the probes). The trans-I, trans-III, and cis-V configurations showed abundances of approximately $38 \%, 13 \%$ and $49 \%$, respectively. Thus, C-functionalization appears to have a very minor impact in the proportion of the different isomers of $\mathrm{Zn}(\mathbf{D M C}) \mathrm{Cl}_{2}$ (Table 2).

The NMR spectra of the $\mathrm{Zn}(\mathrm{II})$ complexes of tetramethylated derivatives showed poorly resolved signals for the $\alpha-\mathrm{CH}_{2}-\mathrm{N}$ and methyl carbon atoms, a problem likely associated to exchange processes. In order to be able to characterize these complexes, NMR spectra were recorded in $\mathrm{CD}_{3} \mathrm{OD}$ at $-50{ }^{\circ} \mathrm{C}$ (Figures 6 , S32-S33 and 2D NMR experiments shown in Figures S34S36 and Table S6). Under these conditions, the two complexes $\mathrm{Zn}(\mathbf{T M C}) \mathrm{Cl}_{2}$ and $\mathrm{Zn}$ (TMC-E) $\mathrm{Cl}_{2}$ display a single isomer in solution, which can be attributed to the trans-I isomer, since no other configuration has been reported so far for a $\mathrm{Zn}$ (II) complex of tetramethyl derivatives. This is supported by DFT calculations that indicate a stabilization of the trans-I isomer on increasing the number of methyl groups of the ligand. Indeed, the relative free energy of the trans-I isomer with respect to the trans-III one takes values of $+2.3,-3.7$ and $-15.2 \mathrm{kJmol}^{-1}$ on going from $[\mathrm{Zn}(\mathbf{c y c l a m}) \mathrm{Cl}]^{+}$to $\left[\mathrm{Zn}(\mathbf{D M C}) \mathrm{Cl}^{+}\right.$and to $[\mathrm{Zn}(\mathbf{T M C}) \mathrm{Cl}]^{+}$. Thus, the alkylation of the $\mathrm{N}$ atoms of cyclam with two methyl groups induces a moderate stabilization of the trans-I isomer, in agreement with the NMR data, while the incorporation of four methyl groups causes a remarkable stabilization of the trans-I isomer (Table 2).

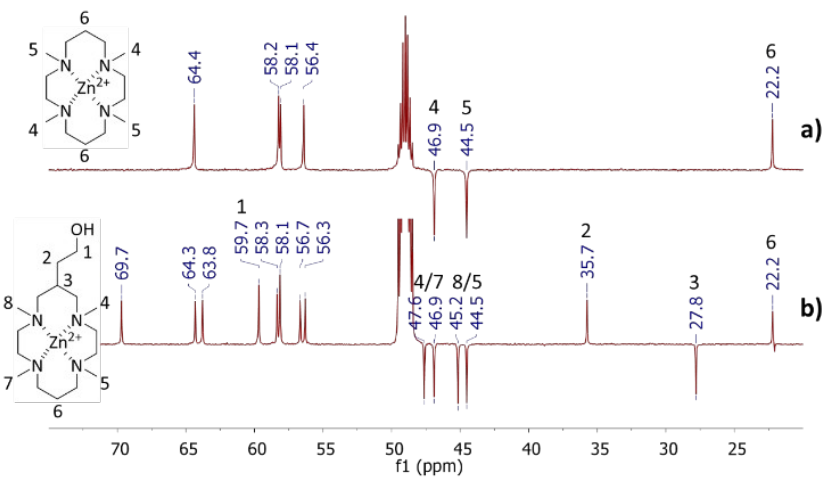

Figure 6. ${ }^{13} \mathrm{C}$ NMR spectra (Jmod, $125 \mathrm{MHz}, \mathrm{CD}_{3} \mathrm{OD}$, $223 \mathrm{~K}$ ) of (a) $\mathrm{Zn}(\mathbf{T M C}) \mathrm{Cl}_{2}$ and (b) $\mathrm{Zn}(\mathbf{T M C}-\mathbf{E}) \mathrm{Cl}_{2}$.

The ${ }^{13} \mathrm{C}$ NMR spectrum of $\mathrm{Zn}(\mathbf{T M C})^{2+}$ indicates an effective $C_{2}$ symmetry in solution, where the symmetry axis is perpendicular to the macrocyclic main plane. As a result, the $\mathrm{Zn}-\mathrm{N}$ bonds (and methyl groups) in trans position are magnetically equivalent. The presence of the hydroxyethyl substituent in Zn(TMC-E) ${ }^{2+}$ lowers the symmetry of the complex, and thus four signals are observed for the methyl groups in the ${ }^{13} \mathrm{C}$ NMR spectrum (spectrum B, Figure 6). These is consistent with a trans-I conformation of the complexes, where the metal sits above the plane containing the nitrogen atoms, pointing to a square-pyramidal coordination geometry with a distorted square base. The broad signals observed in the NMR spectra recorded in $D_{2} \mathrm{O}$ at $298 \mathrm{~K}$ are likely related to the dynamic averaging of the ${ }^{13} \mathrm{C}$ NMR signals from a $C_{2}$ to a $C_{2 v}$ symmetry, which requires the inversion of the central five-membered chelate rings $(\delta \leftrightarrow \lambda$ interconversion).

The reinforced complexes can adopt only the cis- $\mathrm{V}$ conformation in solution. However, the Cfunctionalized cyclam derivatives can form two isomers (syn and anti), depending on the relative orientation of the $C$-functionalization and the ethylene bridge connecting two opposite $\mathrm{N}$ atoms of the macrocycle (vide supra). Thus, we performed NMR studies to identify the two isomers and to analyze if their relative population changes upon complexation. The ${ }^{13} \mathrm{C}$ NMR Jmod spectra of the $\mathrm{Zn}(\mathbf{C B}-\mathbf{c y c l a m})^{2+}$ and $\mathrm{Zn}$ (CBcyclam-E $)^{2+}$ complexes obtained in $\mathrm{D}_{2} \mathrm{O}$ at $25^{\circ} \mathrm{C}$ and are shown in Figure 7 and Figures S37 and S38. As expected, Zn(CB-cyclam $)^{2+}$ presents only one species, while $\mathrm{Zn}(\mathbf{C B}-\mathbf{c y c l a m}-\mathbf{E})^{2+}$ presents two species in solution with a 2:1 ratio, as observed for the free ligand (67/33). 


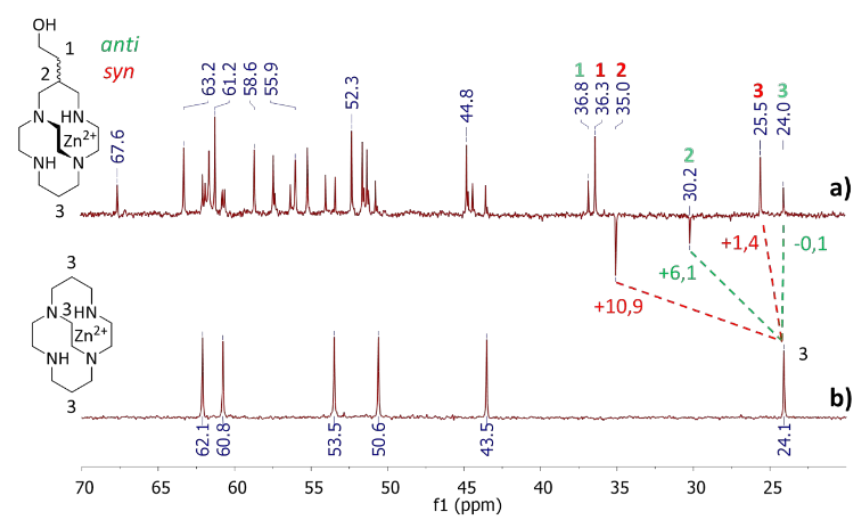

Figure 7. ${ }^{13} \mathrm{C}$ NMR spectra (Jmod, $125 \mathrm{MHz}, \mathrm{D}_{2} \mathrm{O}$, $298 \mathrm{~K})$ of $\mathrm{Zn}(\text { CB-cyclam-E })^{2+}$ and Zn(CB-cyclam $)^{2+}$.

Table 3. ${ }^{13} \mathrm{C}$ NMR chemical shifts (ppm) of the two isomers of Zn(CB-Cyclam-E $)^{2+}$ and Zn(CB-DMC-E $)^{2+}$ and their assignments using the chemical shifts calculated at the TPSSh/Def2-TZVPP level.

\begin{tabular}{|c|c|c|c|c|}
\hline & $\mathrm{Zn}(\mathbf{C}$ & yclam & & \\
\hline & anti & & syn & \\
\hline & $\delta^{\exp }$ & $\delta^{\text {cal }}$ & $\delta^{\exp }$ & $\delta^{\text {cal }}$ \\
\hline$\beta-\mathrm{CH}_{2}-\mathrm{N}$ & 24.0 & 23.2 & 25.5 & 25.1 \\
\hline$\beta-\mathrm{CH}-\mathrm{N}$ & 30.2 & 31.7 & 35.0 & 38.6 \\
\hline$\beta-\mathrm{CH}_{2}-\mathrm{OH}$ & 36.8 & 36.1 & 36.3 & 33.1 \\
\hline & $\mathrm{Zn}(\mathbf{C}$ & MC-E & & \\
\hline & anti & & syn & \\
\hline & $\delta^{\exp }$ & $\delta^{\text {cal }}$ & $\delta^{\exp }$ & $\delta^{\text {cal }}$ \\
\hline$\beta-\mathrm{CH}_{2}-\mathrm{N}$ & 24.8 & 25.4 & 24.9 & 24.7 \\
\hline $\mathrm{CH}-\beta-\mathrm{N}$ & 30.9 & 32.4 & 34.4 & 37.2 \\
\hline$\beta-\mathrm{CH}_{2}-\mathrm{OH}$ & 36.8 & 35.1 & 37.0 & 34.1 \\
\hline $\mathrm{CH}_{3}$ & 49.7 & 46.4 & 48.2 & 46.5 \\
\hline $\mathrm{CH}_{3}$ & 49.8 & 51.0 & 49.9 & 49.0 \\
\hline$\alpha-\mathrm{CH}_{2}-\mathrm{OH}$ & 61.8 & 63.5 & 61.8 & 63.7 \\
\hline
\end{tabular}

The anti and syn isomers were assigned based on information gathered from the crystallographic structures and DFT calculations. The structure of the anti isomer of $\mathrm{Zn}(\mathbf{C B}-\mathbf{c y c l a m}-\mathbf{E})^{2+}$ is closer to that of $\mathrm{Zn}(\mathbf{C B}-\mathbf{c y c l a m})^{2+}$, with the two sixmembered chelate rings adopting chair conformations. The $\mathrm{CH}_{2}$ signals corresponding to the $\beta-\mathrm{CH}-\mathrm{N}$ carbon atom in the two isomers are observed at 25.5 and $24.0 \mathrm{ppm}$. These chemical shifts are similar to that observed for Zn(CBcyclam $)^{2+}(24.1 \mathrm{ppm})$. The chemical shifts of the $\mathrm{CH} \beta-\mathrm{CH}-\mathrm{N}$ carbon atom in the two isomers differ significantly (30.2 and $35.0 \mathrm{ppm}$ ). This signal is more deshielded for one of the isomers, which we assigned as the syn isomer, as a result of the twist-boat conformation of the six-membered chelate ring. DFT calculations (Table 3) support this assignment. The complexation reaction does not allow isomer interconversion, as a result of the particularly constrained geometry of the ligand.

The same overlay of NMR spectra recorded in $\mathrm{D}_{2} \mathrm{O}$ at $25{ }^{\circ} \mathrm{C}$ was done for $\mathrm{Zn}(\text { CB-DMC })^{2+}$ and

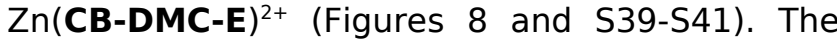
syn and anti isomers of the CB-DMC-E ligand were separated during their synthesis, and thus the complexation reaction was carried out independently for each species. Complexation led to a single isomer in solution, demonstrating that no isomerization occurred during the complexation. This is related to the presence of the ethylene bridge of the ligand, which constrains the macrocyclic structure and prevents isomerization.

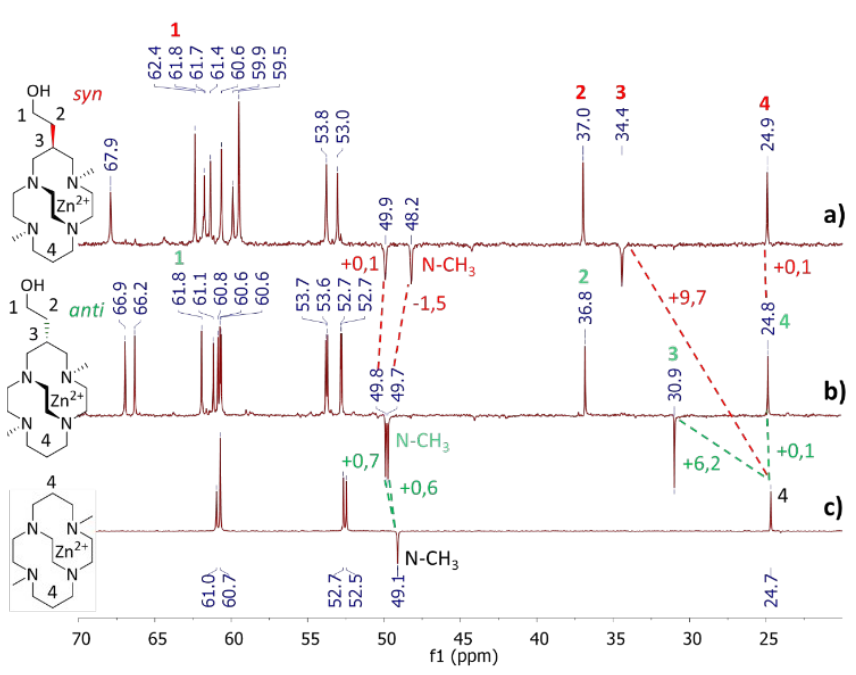

Figure 8. ${ }^{13} \mathrm{C}$ NMR (Jmod, $125 \mathrm{MHz}, \mathrm{D}_{2} \mathrm{O}, 298 \mathrm{~K}$ ) spectra of $\mathrm{Zn}(\mathbf{C B}-\mathrm{DMC})^{2+}$, anti-Zn(CB-DMC-E $)^{2+}$, and syn-Zn(CB-DMC$\mathrm{E})^{2+}$

The ${ }^{13} \mathrm{C}$ NMR spectra of $\mathrm{Zn}(\mathbf{C B}-\mathrm{DM} \text { M-E })^{2+}$ evidence a chemical shift of $+6.2 \mathrm{ppm}$ for the $\beta$ $\mathrm{CH}-\mathrm{N}$ carbon atom of the anti isomer with respect to $\mathrm{Zn}(\mathbf{C B}-\mathbf{D M C})^{2+}$, while for the syn isomer a shift of $+9.7 \mathrm{ppm}$ was observed. Each isomer was assigned by the chemical shift of this signal compared to its analogue in the $\mathrm{Zn}(\mathbf{C B}-\mathbf{D M C})^{2+}$ complex. However, the chemical shift of the $\beta$ $\mathrm{CH}_{2}-\mathrm{N}$ carbon atom of the two $C$-functionalized complexes remains very similar to that of $\mathrm{Zn}$ (CBDMC $^{2+}(+0.1 \mathrm{ppm}$ and $+0.2 \mathrm{ppm})$. The methyl groups are only slightly shifted for the anti-isomer ( +0.6 and $+0.7 \mathrm{ppm})$, while they are more distinct for the syn-isomer (+ 0.1 and $-1.5 \mathrm{ppm})$. The $C$ nuclei of the hydroxyethyl chain are very slightly impacted by the conformation of the complex: the signals due to the $\beta-\mathrm{CH}_{2}-\mathrm{OH}$ carbon atom in the two isomers differ by $0.2 \mathrm{ppm}$, while the $\alpha-\mathrm{CH}_{2}-\mathrm{OH}$ carbon atoms present the same chemical shift (61.8 ppm).

Electronic spectra of $\mathbf{C u}(\mathrm{II})$ complexes. Absorption spectra in the visible region were recorded for all $\mathrm{Cu}$ (II) complexes in aqueous solutions at neutral $\mathrm{pH}$ and at $25 \stackrel{\circ}{ } \mathrm{C}$. The $\mathrm{Cu}$ (cyclam) $\mathrm{Cl}_{2}$ and $\mathrm{Cu}$ (cyclam-E) $\mathrm{Cl}_{2}$ complexes are pink, $\mathrm{Cu}(\mathbf{D M C}) \mathrm{Cl}_{2}$ and $\mathrm{Cu}(\mathbf{D M C}-\mathbf{E}) \mathrm{Cl}_{2}$ are purple, while the TMC and TMC-E complexes are blue as well as all the cross-bridged cyclam complexes (Figures $\mathrm{S} 42$ and S43). Broad $d-d$ absorption bands were observed with maxima 
ranging from 507 to $628 \mathrm{~nm}$. The strongest ligand field for these copper complexes was found for the cyclam complexes, whereas the weakest ligand field was found for the $\mathrm{Cu}(\mathrm{II})($ TMC) and $\mathrm{Cu}$ (II)(CB-DMC) complexes. The position and intensity of the bands exclude regular octahedral or tetragonal geometries. ${ }^{45-48}$ However, it is difficult to infer the geometry of $\mathrm{Cu}$ (II) complexes from electronic spectra alone, as they vary with the distortion within a given coordination number, due to the plasticity of the $\mathrm{Cu}$ (II) coordination environment. ${ }^{45}$ Thus, X-band EPR spectra of the same solutions were recorded.

X-band EPR spectra of frozen 1:1 water/DMF solutions of five $\mathrm{Cu}(\mathrm{II})$ complexes of cyclam and CB-cyclam derivatives containing 6-ethanoyl groups appended to the framework of the macrocycle were obtained at about 140-160 K. The spectra of the corresponding parent macrocyclic complexes were acquired for comparison using the same experimental conditions (Figures 8 and 9). All the complexes of cyclam derivatives showed the presence of a single paramagnetic species, while all the CBcyclam ones exhibit two species, although the amount of the second species for the CB-cyclamE complex is so small that it was not possible to determine its parameters. The spectra of all complexes do not present superhyperfine splitting resulting from coupling with the nitrogen atoms of the ligands. Spectroscopic absorption data, hyperfine coupling constants $A_{\mathrm{i}}(\mathrm{i}=1-3)$ and $g_{\mathrm{i}}$ values obtained by EPR spectral simulation using SpinCount ${ }^{49}$ are compiled in Table 4.

All spectra exhibit three well resolved lines of the four expected at low field, arising from interaction of the unpaired electron spin with the copper nucleus $(I=3 / 2)$ where accurately values of $g_{1}$ and $A_{1}$ (or $g_{\|}$and $A_{\|}$for molecules of axial character) are obtained. The fourth copper line is completely overlapped by the much stronger and not resolved bands of the high-field region of the spectrum, which provide the $g_{2}, g_{3}, A_{2}$ and $A_{3}$ (or $g_{\perp}$ and $A_{\perp}$ ) values. Simulation of the spectra showed rhombic symmetry for all complexes studied, as expected from the non-axial character of the molecules, except for the $\mathrm{Cu}(\mathrm{II})$ cyclam and cyclam-E complexes.
Spectral simulations show that $g_{1}>\left(g_{2}+g_{3}\right) / 2$ (or $g_{\|}>g_{\perp}$ ) and the lowest $g>2.035$ value for almost all studied complexes, except for one of the species of the four cross-bridged complexes studied, see below. This relation of $g$ values are characteristic of mononuclear $\mathrm{Cu}(\mathrm{II})$ complexes in rhombic or axial symmetry with elongation of the axial bonds and a $d_{x} 2_{-y}^{2}$ ground state. Elongated rhombic-octahedral, tetragonal, distorted bicapped square pyramidal, or distorted square pyramidal symmetries would be consistent with these data. ${ }^{45-48,50-55}$ 
Table 4. EPR parameters for $\mathrm{Cu}(\mathrm{II})$ complexes of the cyclam derivatives studied in this work at $\sim 140 \mathrm{~K}$ in water/DMF $(1: 1 \mathrm{~V} / \mathrm{v})$ and parameters obtained with DFT calculations (BHandHLYP/Def2_TZVPP).

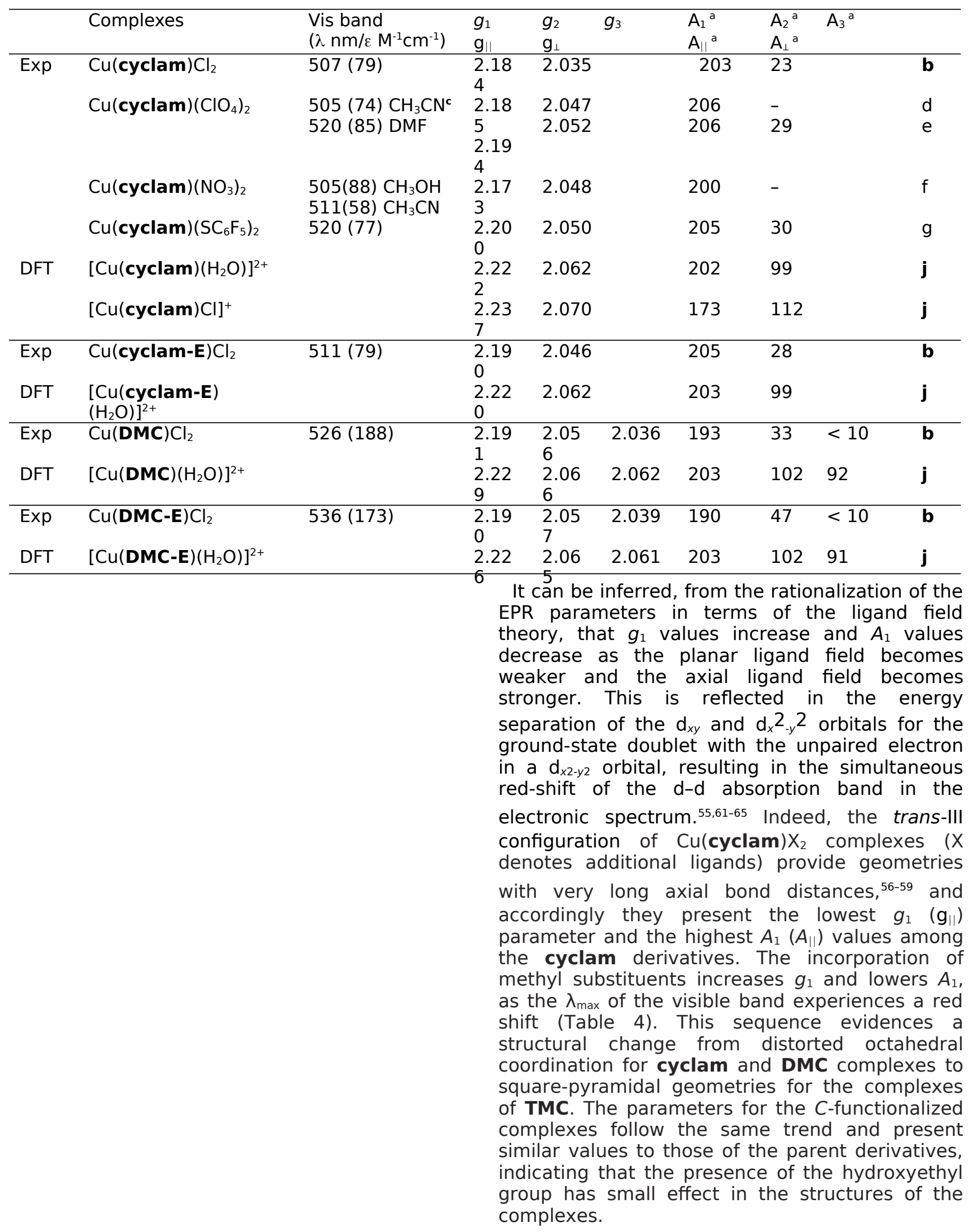


The crystal structures of $\mathrm{Cu}($ cyclam $) \mathrm{X}_{2}$ complexes (independently of the type of axial bonding) show the $\mathrm{Cu}(\mathrm{II})$ ion in six-coordinate tetragonally elongated environments, with strong equatorial $\mathrm{Cu}-\mathrm{N}$ bonds in a square-planar arrangement. ${ }^{11,56-59,66-69}$ The optical and EPR spectra of the famplexesreveal ng effects of the axial ligands

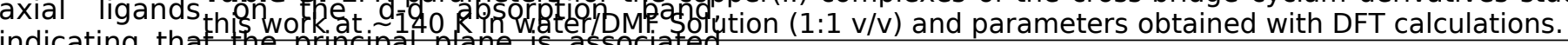

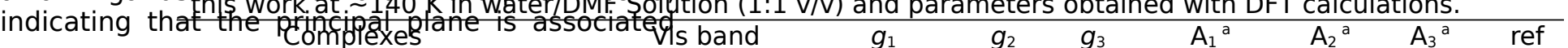

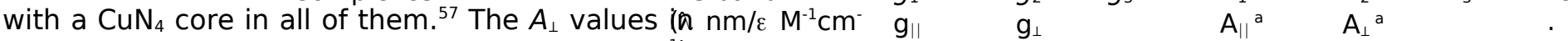

particular point to- weak axial interactions. ${ }^{57}$ Oh the other hand, the cu(TMic) X ${ }_{2}$ complexes almost only form trans-I diastereoisomers, ${ }^{19,60,70}$ although ${ }^{5}$ the trans-III isomer was isolated in the presence

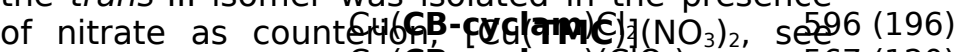
Table 4 , note $i .^{19}$

$\left.\mathrm{Cu}(\mathrm{CB}-\mathrm{cyclam})\left(\mathrm{ClO}_{4}\right)_{2}\right)_{2}, 567$ (120)

DFT calculations were (Carried out)in an attempt

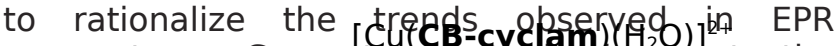
parameters. Geometry optmizations at the

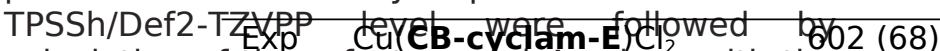
calculation of the $g$ factors ahd $A$ values with the

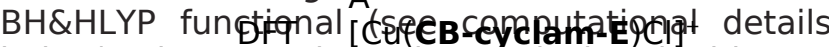
below). The $g$ - and $A$-values calculated with DFT methods were shownctodes-dyelamiegsitive to the nature of the functier(a) $\}_{3}^{2+}$ in particular to the

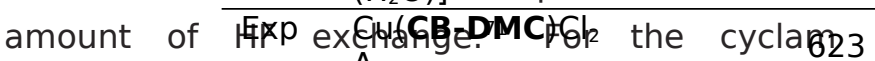
complexes investigatted here, the BH\&HLYSR functional provided goodestimates of both $g^{\mathrm{B}}$ and $A$-values (Table 4). Our calculations provide very similar $g$ - values for the $\left[\mathrm{Cu}(\right.$ cyclam $\left.) \mathrm{Cl}_{2}\right]$ and [Cu(cyclam) $\left.\left(\mathrm{H}_{2} \mathrm{O}\right)_{2}\right]^{2+}$ systems (trans-III), while for $A_{1}$ the latter provides a better agreement with the experiment. The $\left[\mathrm{Cu}(\mathbf{c y c l a m}-\mathbf{E})\left(\mathrm{H}_{2} \mathrm{O}\right)_{2}\right]^{2+}$ system affords virtually the same EPR parameters, in line with the experimental evidence. The [Cu(TMC) $\left.\left(\mathrm{H}_{2} \mathrm{O}\right)\right]^{2+}$ and $\left[\mathrm{Cu}(\text { TMC-E })\left(\mathrm{H}_{2} \mathrm{O}\right)\right]^{2+}$ systems present increased $g_{1}$ and decreased $A_{1}$ values compared to cyclam complexes. This correlates with a stronger axial $\mathrm{Cu}-\mathrm{OH}_{2}$ bond in the methylated complexes (2.22 and $2.47 \AA$ for [Cu(TMC) $\left.\left(\mathrm{H}_{2} \mathrm{O}\right)\right]^{2+}$ and $\left[\mathrm{Cu}(\text { cyclam })\left(\mathrm{H}_{2} \mathrm{O}\right)_{2}\right]^{2+}$, respectively). The opposite trend is observed for the $\mathrm{Cu}-\mathrm{N}$ bonds, which are shorter fort $\left[\mathrm{Cu}(\text { cyclam })\left(\mathrm{H}_{2} \mathrm{O}\right)_{2}\right]^{2+}(2.04$ $\AA)$ than for $\left[\mathrm{Cu}(\mathrm{TMC})\left(\mathrm{H}_{2} \mathrm{O}\right)\right]^{2+}(2.14-2.20 \AA)$. The intermediate $A_{1}$ values observed experimentally for the DMC and DMC-E complexes is likely related to the octahedral deformation introduced by the presence of two methyl groups.

Most $\mathrm{Cu}(\mathrm{II})$ complexes of cross-bridged cyclam type structures revealed the four macrocyclic amines coordinated to the metal center within its molecular cleft in a cis-V configuration and one or two additional monodentate ligands completing the metal coordination environment. The macrocycle design excludes trans conformations. The common geometries are intermediate between square pyramidal and trigonal bipyramidal or distorted octahedral. ${ }^{25,26}$ The $\mathrm{X}$ band EPR spectra of the four cross-bridged $\mathrm{Cu}(\mathrm{II})$ complexes studied showed the presence of two complex species (A and $\mathbf{B})$ in different percentage, except for the CB-cyclam-E complex, see Figure 9. The spectra were successfully simulated with the parameters listed in Table 5 .

$\begin{array}{lllllll}2.196 & 2.09 & 2.03 & 150.7 & 43 & <10 & \text { b } \\ & 7 & 6 & & & & \\ 1.995 & 2.12 & 2.20 & <10 & 46 & 159 . & \\ & 1 & 9 & & & 3 & \\ - & & - & & & & \text { c }\end{array}$

$\begin{array}{llllllll}2.013 & 2.17 & 2.24 & 12 & 66 & 194 & \text { d }\end{array}$

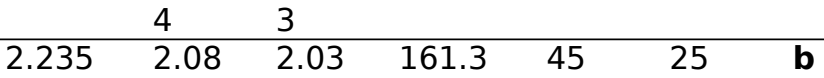

$\begin{array}{lllllll}2.241 & 2.15 & 2.01 & 162 & 100 & 8 & \text { d }\end{array}$

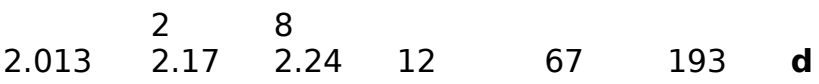

(52), 675

\begin{tabular}{|c|c|c|c|c|c|}
\hline 2.268 & 2.058 & & 153.2 & 15 & b \\
\hline 2.017 & $\begin{array}{l}2.12 \\
4\end{array}$ & $\begin{array}{l}2.22 \\
0\end{array}$ & $<10$ & 20 & $\begin{array}{l}163 . \\
7\end{array}$ \\
\hline 2.098 & $\begin{array}{l}2.28 \\
4\end{array}$ & & & & C \\
\hline
\end{tabular}
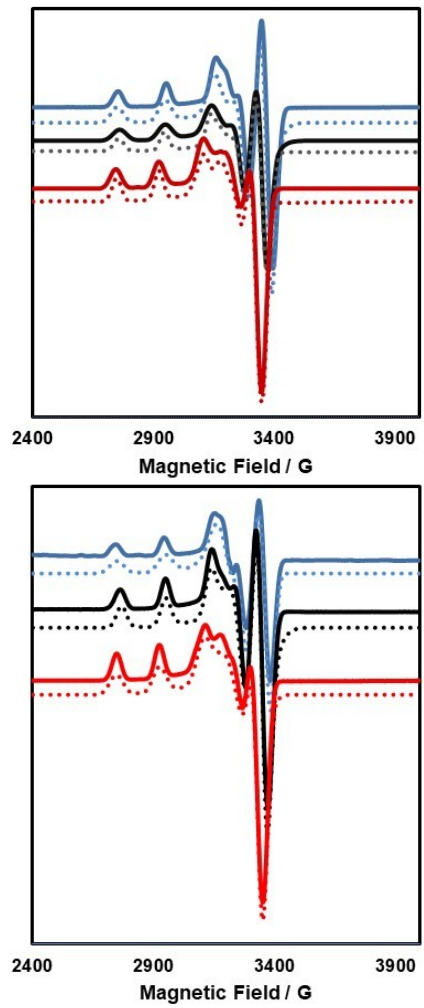

Figure 8. X-band EPR spectra of the $\mathrm{Cu}(\mathrm{II})$ complexes of cyclam (in blue), DMC (black) and TMC (in red) at top and cyclam-E (in blue), DMC-E
$2.146 \quad 2.27$

$\begin{array}{lllllll}2.242 & 2.15 & 2.01 & 164 & 98 & 4 & \text { d }\end{array}$ 
(black) and TMC-E (in red) down, in a frozen water/ DMF solution $(1: 1 \mathrm{v} / \mathrm{v})$ recorded at $\sim 140 \mathrm{~K}$ and the simulated ones (below the corresponding experimental spectra in dots). Experimental conditions: at $\mathrm{pH} \approx 7$ and concentration $20 \mathrm{mM}$. Microwave power of $2.0 \mathrm{~mW}$, modulation amplitude of $0.1 \mathrm{mT}$, and the frequency (v) was $9.31 \mathrm{GHz}$.

One of the complex species of each sample (indicated by $\mathbf{A}$ in Table 5 ) follows the sequence of non-bridged compounds, with the EPR parameters obtained by simulation being very similar to those of TMC complexes. This is consistent with a $\mathrm{d}_{x}{ }^{2}{ }^{2}$ ground state with elongated rhombic octahedral or distorted square pyramidal geometries. However, the crossbridged derivatives adopt much more distorted geometries than the non-bridged analogues, as indicated by the much lower $A_{1}$ values (150.7 to $165.4 \times 10^{-4} \mathrm{~cm}^{-1}$ for cross-bridged complexes compared to 181.6 to $184.8 \times 10^{-4} \mathrm{~cm}^{-1}$ for TMC complexes). On the other hand, when the spectroscopic parameters of the cross-bridged complexes are compared with those of the first series of cyclam-DMC-TMC ones, it is possible to observe that they present larger $g_{1}$ parameters. Although the data point also to square-pyramidal geometries, the drastic decrease in $A_{1}$ can be interpreted by geometrical distortions of the quadrangular plane towards a trigonal bipyramidal geometry. In fact, it was demonstrated that the EPR parameters are quite sensitive to the introduction of a distortion towards a trigonal bipyramid, leading to a significant decrease in $A_{1}$ values while small effects are found in $A_{2}$ and $A_{3}{ }^{65,72-74}$

The EPR parameters of the second complex species obtained also by simulation, indicated by B in Table 5, revealed that they have reversed spectra in which $g_{3}>g_{2} \gg g_{1} \approx 2.00$, or $g_{\perp}>g_{\|}$. The values of $\mathrm{R}>1$ (with $\mathrm{R}=\left(g_{2}-g_{1}\right) /\left(g_{3}-g_{2}\right)$ ) as well as the values of the hyperfine splitting parameters, are indicative that the greater contribution to the ground state arises from the $\mathrm{d}_{\mathrm{z}}{ }^{2}$ orbital, ${ }^{52,55,75,76}$ characteristic of axialcompressed geometries, such as distorted compressed octahedral or trigonal bipyramidal. ${ }^{45}$ $47,52,55,75-77$ Given the very rigid nature of the crossbridge ligands, which imposes a cis- $\mathrm{V}$ conformation, the two species present in solution are likely related to the presence of different ligands that complete the metal coordination environment. To test this hypothesis, we calculated the EPR parameters of the different complexes including either a water molecule or a chloride anion as the fifth ligand. The EPR parameters calculated for the complexes containing a coordinated chloride ligand appear to be closer to those determined for species $A$ in the case of CB-cyclam and CB-DMC, in particular because of the lower $A_{1} / A_{3}$ and $g_{2}$ values. However, the situation is not that clear for the CB-DMC-E complex, which may be related to the presence of syn and anti isomers of the complexes. Nevertheless, it is probable that the presence of two species in solution is related to chloride coordination in the frozen solution.

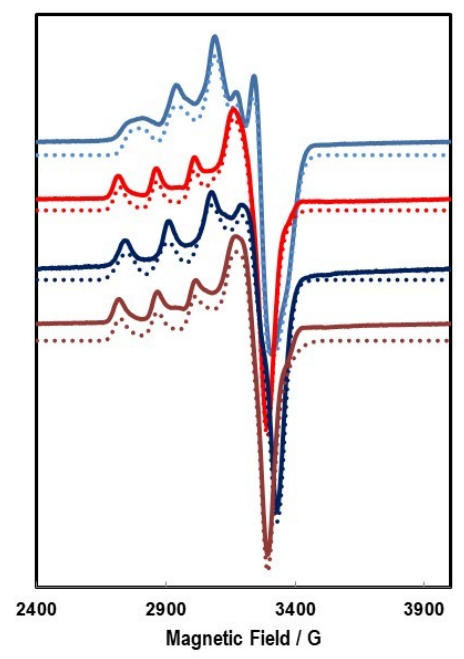

Figure 9. X-band EPR spectra of the $\mathrm{Cu}$ (II) complexes of CB-cyclam and CB-cyclam-E (in blue), CB-DMC (in red) and CB-DMC-E (in brown) in a frozen water/DMF solution $(1: 1 \mathrm{v} / \mathrm{v})$ recorded at $\sim 140 \mathrm{~K}$ and the simulated ones (below the corresponding experimental spectra in dots). Experimental conditions: at $\mathrm{pH} \approx 7$ and concentration $20 \mathrm{mM}$. Microwave power of $2.0 \mathrm{~mW}$, modulation amplitude of $0.1 \mathrm{mT}$, and the frequency (v) was $9.31 \mathrm{GHz}$.

Dissociation of copper complexes in acidic media. The kinetic inertness of the copper complexes was studied through acid-mediated dissociation experiments followed by UV-Visible absorption spectroscopy $\left(\mathrm{HCl} 5 \mathrm{M}, 30^{\circ} \mathrm{C}, 50^{\circ} \mathrm{C}\right.$ and $90^{\circ} \mathrm{C}$, Table 6 and Figures S44-S45). The calculated half-life time of $\mathrm{Cu}(\mathbf{c y c l a m})^{2+}$, trans-I$\mathrm{Cu}(\mathbf{T M C})^{2+}$ and $\mathrm{Cu}(\mathbf{C B}-\mathbf{c y c l a m})^{2+}$ are consistent with the values reported in the literature. ${ }^{78,79}$ The $\mathrm{Cu}(\mathbf{D M C})^{2+}$ complex shows lower inertness than the complex with cyclam, which in turn shows a half-life very similar to that of the TMC complex. Thus, the functionalization with methyl groups is not the only factor that controls the acid-assisted dissociation of these complexes. Indeed, the trans-III-Cu(TMC) ${ }^{2+}$ complex presents a very high half-life, similar to that of $\mathrm{Cu}(\text { cyclam })^{2+}$, suggesting that an octahedral geometry leads to an enhanced inertness. All the copper(II) complexes of the $C$-functionalized derivatives present a higher resistance towards dissociation than the "original" cyclam analogues, indicating that the presence of ethanol moiety on the macrocycle backbone leads to a significant increase in kinetic inertness. This is likely related 
to a more rigid metal coordination environment originated by the presence of the $C$-appended functionality. All cross-bridged complex derivatives resisted more drastic conditions and have been studied at $70{ }^{\circ} \mathrm{C}$. They show similar half-life times, meaning that the major structural contribution to the inertness of the complexes mainly is related to the presence of the ethylene cross-bridge, rather than the presence of methyl groups and/or the $C$-appended arm.

Table 6. Calculated half-life time of copper complexes studied in different hydrochloric acid media from Visible spectroscopy experiments.

\begin{tabular}{|c|c|}
\hline Conditions/ Complexes & $t_{1 / 2}$ \\
\hline \multicolumn{2}{|l|}{$5 \mathrm{M} \mathrm{HCl}$ at $30^{\circ} \mathrm{C}$} \\
\hline $\mathrm{Cu}(\mathbf{T M C})^{2+}($ trans-I) & $<2$ \\
\hline $\mathrm{Cu}(\mathbf{T M C}-\mathbf{E})^{2+}\left(\operatorname{trans}^{-\mathrm{I})}\right.$ & $<2$ \\
\hline \multicolumn{2}{|l|}{$5 \mathrm{M} \mathrm{HCl}$ at $50{ }^{\circ} \mathrm{C}$} \\
\hline $\mathrm{Cu}(\mathbf{D M C})^{2+}$ & 183 \\
\hline $\mathrm{Cu}(\mathbf{T M C})^{2+}($ trans-III) & 374 \\
\hline $\mathrm{Cu}(\text { cyclam })^{2+}$ & 384 \\
\hline $\mathrm{Cu}(\mathbf{D M C}-\mathbf{E})^{2+}$ & 438 \\
\hline $\mathrm{Cu}(\text { cyclam-E })^{2+}$ & 579 \\
\hline $\mathrm{Cu}(\mathbf{T M C}-\mathbf{E})^{2+}($ trans$-\mathrm{III})$ & 699 \\
\hline \multicolumn{2}{|l|}{$5 \mathrm{M} \mathrm{HCl}$ at $70^{\circ} \mathrm{C}$} \\
\hline $\mathrm{Cu}(\text { CB-cyclam-E })^{2+}$ & 128 \\
\hline $\mathrm{Cu}(\mathbf{C B}-\mathbf{D M C})^{2+}$ & 133 \\
\hline $\mathrm{Cu}(\mathbf{C B}-\mathbf{c y c l a m})^{2+}$ & 140 \\
\hline Cu(CB-DMC-E $)^{2+}$ & 141 \\
\hline
\end{tabular}

Electrochemical investigation of $\mathrm{Cu}(\mathrm{II})$ complexes. The redox behavior of the nonbridged copper(II) complexes was investigated by cyclic voltammetry (CV) in $\mathrm{CH}_{3} \mathrm{CN}$ containing tetra- $n$-butylammonium hexafluorophosphate $\left(\mathrm{TBAPF}_{6}, 0.1 \mathrm{M}\right)$ as supporting electrolyte. The CV curves of $\mathrm{Cu}(\mathbf{T M C})^{2+}$ and $\mathrm{Cu}(\mathbf{T M C}-\mathbf{E})^{2+}$ recorded at a scan rate of $0.1 \mathrm{~V}^{-\mathrm{s}^{-1}}$ (Figure 10) exhibit a similar behavior with an irreversible reduction process at $E_{p c}=-0.87 \mathrm{~V}$ vs. $\mathrm{Ag}^{+} / \mathrm{Ag}$ for both complexes attributed to the formation of the corresponding $\mathrm{Cu}(\mathrm{I})$ complexes that are reversibly reoxidized during the reverse scan at $E_{1 / 2}=$ $0.38 \mathrm{~V}$ and $-0.29 \mathrm{~V}$ respectively. In accordance with previous studies on tetramethyl-cyclam $\mathrm{Cu}$ (II) $\left(\mathrm{Cu}(\mathbf{T M C})^{2+}\right)^{80}$ and other related tetra- $N$ substituted-Cyclam Cu(II) complexes, ${ }^{81,82}$ these CV curves indicate that upon the initial electron transfer, the electrogenerated $\mathrm{Cu}(\mathrm{I})$ complexes undergo rearrangements of their coordination spheres (isomerizations) in order to stabilize the $\mathrm{Cu}(\mathrm{I})$ environment, certainly with a coordination number of 4 , which usually favors coordination of the $\mathrm{Cu}^{+}$ion. The stable $\mathrm{Cu}(\mathrm{I})$ complexes can then be reoxidized at higher potentials, (around $-0.3 \mathrm{~V}$ ) for both $\mathrm{Cu}$ (TMC) and $\mathrm{Cu}$ (TMC-E) systems. The slight difference in the oxidation potential of the new $\mathrm{Cu}(\mathrm{I})$ forms of the two complexes indicates that the introduction of the pendant arm certainly plays a role in the coordination mode and/or the kinetics of the rearrangements. In addition, as was observed with $\mathrm{Cu}(\mathbf{T M C})^{2+},{ }^{11}$ when the scan rate of the $\mathrm{CV}$ experiment of $\mathrm{Cu}(\mathrm{TMC}-\mathbf{E})^{2+}$ was increased, the signal of the stabilized $\mathrm{Cu}(\mathrm{I})$ complex around $-0.3 \mathrm{~V}$ progressively decreased and could not be observed above $10 \mathrm{~V} \cdot \mathrm{s}^{-1}$. This effect is due to the short time of the electrochemical experiment that prevents the formation of this complex (Figure 11).

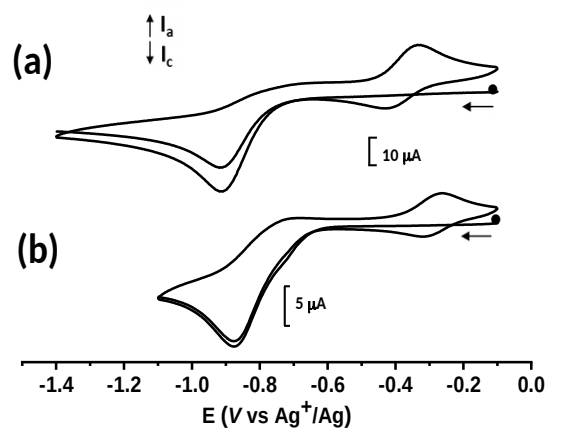

Figure 10. Cyclic voltammograms of (a) $\mathrm{Cu}(\text { TMC })^{2+}$ and (b) $\mathrm{Cu}(\text { TMC-E })^{2+}$ in $\mathrm{CH}_{3} \mathrm{CN}+$ TBAPF $_{6}(0.1 \mathrm{M})$. Scan rate: $0.1{\mathrm{~V} . \mathrm{s}^{-1}}^{-}$.
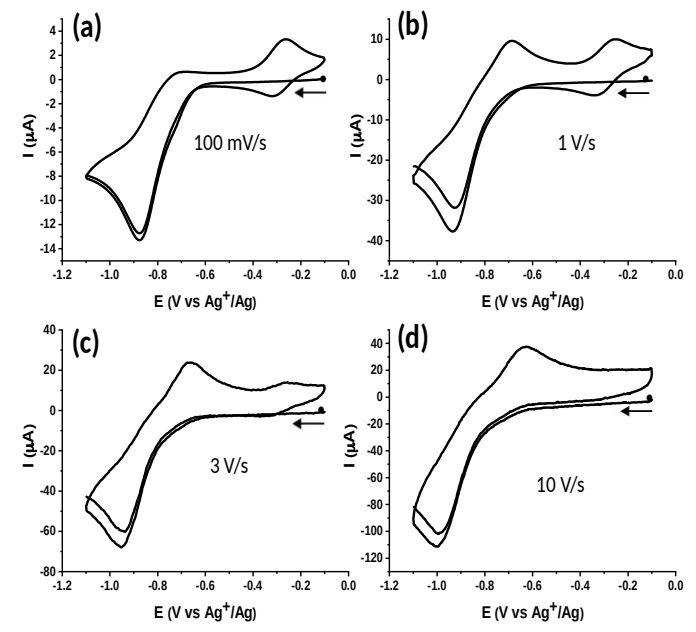

Figure 11. Cyclic voltammograms of $\mathrm{Cu}$ (TMC$\mathbf{E})^{2+}$ in $\mathrm{CH}_{3} \mathrm{CN}+\mathrm{TBAPF}_{6}$ at different scan rates: (a) 0.1 , (b) 1 , (c) 3 , and (d) $10 \mathrm{Vs}^{-1}$.

The voltamogramms of the $\mathrm{Cu}(\mathbf{D M C})^{2+}$ and Cu(DMC-E) ${ }^{2+}$ complexes were also very close in relation to each other with a reduction peak at $E_{p c}$ $=-1.14 \mathrm{~V}$ and $-1.12 \mathrm{~V}$ respectively, associated to ill-defined oxidation signals observed between $1.0 \mathrm{~V}$ and $-0.7 \mathrm{~V}$ on the backward potential scan (Figure S46). Again, this behavior can be attributed to reorganizations of the coordination mode of the system upon reduction of the metal 
center, as was previously reported for other bis$\mathrm{N}$-substituted cyclam-Copper complexes. $^{83}$ $\mathrm{Cu}(\mathbf{c y c l a m}-\mathrm{E})^{2+}$ is poorly soluble in $\mathrm{CH}_{3} \mathrm{CN}+$ TBAPF $_{6}$, and thus was investigated in DMF + TBACl $(0.1 \mathrm{M})$ as supporting electrolyte. Its CV curve (see Supporting Information) displays an electrochemically irreversible reduction peak at $\mathrm{E} p_{c}=-1.72 \mathrm{~V}$ vs. $\mathrm{Ag}^{+} / \mathrm{Ag}$ attributed to the electrodeposition of $\mathrm{Cu}(0)$ at the electrode surface (i.e. electron transfer is accompanied by the demetallation of the complexes at the CV timescale). The formation of $\mathrm{Cu}(0)$ is corroborated by the presence of an anodic redissolution peaks at $-0.9 \mathrm{~V}$ observed during the reverse scan, which corresponds to the oxidation of metallic copper. ${ }^{31,84}$ The electrochemical behavior of [Cu(cyclam)] ${ }^{2+}$ in $\mathrm{CH}_{3} \mathrm{CN}$ appears similar (Figure S47), with a reduction peak at $E p_{c}=-1.72 \mathrm{~V}$ accompanied by ill-defined oxidation signals around $-0.8 \mathrm{~V}$ observed during the reverse scans. At this stage, the nature of the electrogenerated product(s) could not be unambiguously identified.

Overall, the irreversible electrochemical reduction of the metal center was observed for all the investigated complexes at scan rate $=0.1$ V.S $\mathrm{s}^{-1}$, followed by the formation of new $\mathrm{Cu}(\mathrm{I})$ complexes or demetallation reactions observed at the CV time-scale. When comparing the reduction signals of the investigated complexes, one can observe a decrease of the potential peaks when increasing the degree of substitution of the ligands, in agreement with a stabilization of low oxidation states by $N$-methylation of the cyclam core.$^{80}$ In addition, the data indicate that the $C$ functionalized and their corresponding non- $C$ functionalized compounds exhibit very similar CV shapes and redox potentials, although the presence of the side-chain may slightly modify the kinetics and nature of the configuration changes that follow the electron transfer proccess.

\section{CONCLUSION}

Polyazamacrocycles are gaining an increasing relevance in many applications, among which biomedical applications are of particular interest. The design of chelators with improved behavior requires a detailed understanding of the structural properties of the complexes at the molecular level. While the solid state structures may not reflect the exact picture of what happens in solution, they are an important source of information that can be combined with spectroscopic studies in solution. The stereochemical properties of cyclam derivatives are today well understood thanks to the work of Bosnich et al. ${ }^{7}$ followed by those of Whimp et al. ${ }^{8}$ However, most structural studies on these systems rely on information gathered from the $\mathrm{X}$ - ray data, while detailed studies in solution as less common, a remarkable example being the work reported by Sadler et al. in 2003. ${ }^{9}$ Given the importance of bifunctional derivatives of polyazamacrocycles, which are often Cfunctionalized with groups suitable for coupling to an external part, ${ }^{32,33,40,85,86}$ it is important to analyze the influence that the presence of the non-coordinating $C$-pendant group has in the structures of the complexes. We addressed this issue here by providing the first comprehensive structural study involving the $\mathrm{Cu}(\mathrm{II})$ and $\mathrm{Zn}(\mathrm{II})$ complexes of cyclam and methylated and crossbridged constrained derivatives.

The NMR analyzes of the $\mathrm{Zn}$ (II) complexes allowed to identify the different configurations present in solution (trans-I, trans-III, cis-V) depending on the nature of the ligands. The $\mathrm{Zn}$ (cyclam) $\left(\mathrm{Cl}_{2}\right)$ complex exhibits a predominantly trans-III configuration. The addition of methyl groups significantly influences the population of the different isomers. Thus, the dimethylation leads to a stabilization of the transI and cis-V configurations, while tetramethylation leads to the formation of the trans-I isomer only. C-functionalization only slightly influences the relative populations of the isomers present in solution, leading to an increase in the proportion of the cis- $\mathrm{V}$ configuration. The ethylene crossbridge imposes the formation of a complex with a cis-V configuration; nevertheless, the complexation of the $C$-functionalized ligands leads to the formation of two diastereomers, syn and anti, differing by the position of the $C$ function with respect to the ethylene bridge. The EPR and absorption spectra of the $\mathrm{Cu}(\mathrm{L})(\mathrm{X})_{2}{ }^{2+}$ complexes in solution provided useful structural information. The addition of $C$-functionalization leads to a slight structural deformation, but does not significantly modify the geometry of the complexes. In addition, two different geometries were found for the "cross-bridged" complexes depending on the additional ligand completing the coordination sphere of the metal cation. The results were supported by several crystallographic structures as well as by DFT calculations. The dissociation kinetics of the complexes in acidic conditions provided some interesting observations. The methylation of the secondary amine groups has the effect of reducing the half-life of the $\mathrm{Cu}(\mathrm{II})$ complexes, while complexes adopting trans-III configurations are particularly inert, a feature that was not reported before. The presence of $C$ functionalization also leads to a remarkable increase in kinetic inertness. The complexes of a "cross-bridged" derivatives all exhibit very high (and comparable) kinetic inertness. Finally, the electrochemistry study supported our first conclusions and evidenced a stabilization of $\mathrm{Cu}(\mathrm{I})$ by increasing the number of $N$-methyl substituents of the cyclam core. 
The results reported in this paper allow us concluding that the $C$-functionalization of cyclam does not affect significantly the properties of the corresponding $\mathrm{Cu}(\mathrm{II})$ and $\mathrm{Zn}(\mathrm{II})$ complexes, the most remarkable effect being the increased kinetic inertness of C-functionalized cyclam derivatives. This point is of high importance if the $C$-appended group is used as an anchoring function for applications where the cyclam core must remain intact.

\section{EXPERIMENTAL SECTION}

\section{General procedure for the preparation of all ML chelates.}

Ligands were dissolved in pure water and the $\mathrm{pH}$ adjusted to 6-7 with a $\mathrm{HCl}$ solution (1 M). 1.1 equivalent of $\mathrm{MCl}_{2}$ was added and the mixture was stirred at $80{ }^{\circ} \mathrm{C}$ (reflux for cross-bridged derivatives). The $\mathrm{pH}$ was readjusted to 6-7 with $\mathrm{KOH}$ solution $(1 \mathrm{M})$ during the reaction and this process was repeated till the $\mathrm{pH}$ remained constant. Then, water was evaporated in a drybath at $90{ }^{\circ} \mathrm{C}$. Complexes were dissolved in small amounts of $\mathrm{CH}_{3} \mathrm{CN}$ or $\mathrm{MeOH}$ and the insoluble salts were eliminated by filtration (repeated 3-4 times). Finally, compounds were dissolved in 1-2 $\mathrm{mL}$ of pure water and lyophilized. Analyses of the complexes are reported in the Supporting Information.

\section{Material and methods}

Reagents used for synthesis were purchased from Acros Organics ${ }^{\circledR}$ or Sigma-Aldrich ${ }^{\circledR}$ and used without further purification. Ultrapure water was freshly obtained from a Milli-Q dispenser. A solvent purification system was used to dispense dry solvents before each reaction. NMR spectra were recorded at the "Services communs" of the University of Brest. ${ }^{1} \mathrm{H}$ and ${ }^{13} \mathrm{C}$ NMR spectra were recorded using Bruker Avance 500 (500 MHz), Bruker Avance $400(400 \mathrm{MHz})$ or Bruker AMX-3 $300(300 \mathrm{MHz})$ spectrometers. Coupling constants are given in hertz and chemical shifts in ppm.

\section{Spectroscopic Studies}

The Visible spectra of all complexes were measured at 298 or $323 \mathrm{~K}$ on a Jasco V-650 spectrometer in water.

${ }^{1} \mathrm{H},{ }^{13} \mathrm{C}$ and 2D NMR spectra of $\mathrm{Zn}(\mathrm{II})(\mathrm{L})$ complexes were recorded with a Bruker Advance 500 (500 $\mathrm{MHz}$ ) spectrometer in deuterated solvents at fixed temperature.

The EPR spectra of the frozen sample solutions were acquired at 140-160 K on a Bruker EMX 300 spectrometer operating in the $\mathrm{X}$-band and equipped with a continuous-flow cryostat for liquid nitrogen, at a microwave power of $2.0 \mathrm{~mW}$ and a frequency of $9.5 \mathrm{GHz}$.

\section{Mass spectrometry}

The high-resolution mass spectra of compounds were recorded at Institute of Organic and Analytic Chemistry (ICOA, Orleans, France) with a HRMS Q-Tof MaXis instrument, using ESI, APCl, APPI or nano-ESI for ionization. The Low resolution Mass Spectrometry analyses were performed by "Services communs" of the University of Brest on a Waters Synapt XS, source ESI.

\section{Electrochemical measurements.}

Cyclic Voltammetry (CV) and electrolysis experiments were performed with a $\mathrm{CH}$ Instrument potentiostat (CHI 660B), using a standard one-compartment, three-electrode electrochemical cell. Experiments were conducted at $298 \mathrm{~K}$ in $\mathrm{CH}_{3} \mathrm{CN}+$ tetra- $n$ butylammonium hexafluorophosphate $\left(\mathrm{TBAPF}_{6}\right.$, $0.1 \mathrm{M})$ or DMF + tetra- $n$-butylammonium chloride (TBACl, $0.1 \mathrm{M}$ ) as supporting electrolyte. Typically, millimolar solutions of the complexes were used for the electrochemical studies. The counter electrode was a platinum wire and an ALS Co. Ltd. $\mathrm{Ag}^{+} \mid \mathrm{Ag}$ electrode $\left(\left[\mathrm{Ag}^{+}\right]=10^{-2} \mathrm{M}\right.$ in $\left.\mathrm{CH}_{3} \mathrm{CN}\right)$ was used as reference. This electrode was separated from the solution by a bridge compartment. For CV measurements, the working electrode was a 1 $\mathrm{mm}$ diameter platinum disk which was polished with $1^{\llcorner} \mathrm{m}$ diamond paste before each recording. Reference electrodes were calibrated by addition of ferrocene $\left(\mathrm{Fc}^{+} / \mathrm{Fc}\right)$ couple in the solution after each experiment. All measurements were taken in absence of oxygen, by bubbling argon before experiments.

\section{Acid-mediated dissociation}

The dissociation of the copper(II) complexes was studied under pseudo-first order conditions without control of ionic strength by addition of an ultrapure aqueous solution of $\mathrm{HCl} 30 \% \mathrm{w} / \mathrm{w}(9.58$ $M$ ) (in order to obtain a final concentration in the quartz cell of $5 \mathrm{M}$ ) to an aqueous solution of the preformed complex (in order to obtain a final concentration in the quartz cell of $3 \mathrm{mM}$ ). Dissociation was followed by the decreasing intensity of the absorption band of the $d-d$ transition. The data were fitted with OriginPro 9.0 to a first-order exponential decay equation of the form $A_{t}=A_{\infty}+\left(A_{0}-A_{\infty}\right) e^{-k t}$, where $A_{t}, A_{\infty}$, and $A_{0}$ are the absorbances at time $t$, at the end of the reaction, and at the start of the reaction, with $\mathrm{k}=$ $\ln (2) / t_{1 / 2}$.

\section{$X$-ray Diffraction Determinations}

Single-crystal X-ray diffraction data were collected with a Xcalibur 2 CCD 4-circle Diffractometer (Oxford Diffraction) fitted with a graphite monochromated Mo $\mathrm{K} \alpha$ radiation $(\lambda=$ $0.71073 \AA$ A). Data were collected at $170 \mathrm{~K}$. Crystal data and structure refinement details are given in table S1 to table S5. Unit cell determination and data reduction, including interframe scaling, Lorentzian, polarization, empirical absorption, and detector sensitivity corrections, were carried out using attached programs of CrysAlis software 
(Oxford Diffraction). ${ }^{87}$ Structures were solved by direct methods and refined by full matrix leastsquares method on $\mathrm{F} 2$ with the SHELXL97 ${ }^{88}$ suite of programs. The hydrogen atoms were identified at the last step and refined under geometrical restraints and isotropic U-constraints. CCDC 2019881, CCDC 2020197, CCDC 2020207, CCDC 2077672 contain the supplementary crystallographic data for this paper. These data can be obtained free of charge from The Cambridge Crystallographic Data Centre via www.ccdc.cam.ac.uk/data_request/cif.

\section{DFT calculations}

The geometries of the complexes investigated in this work were optimized with the Gaussian $16^{89}$ program package using the TPSSh functional (10\% HF exchange) ${ }^{90}$ and the Def2-TZVPP ${ }^{91}$ basis set. Bulk solvent effects (water) were incorporated using a polarized continuum model ${ }^{92}$ using the default settings implemented in gaussian ( $\mathrm{scrf}=\mathrm{pcm}$; solute cavity defined by universal force field radii (UFF) ${ }^{93}$ scaled with $\alpha=1.1$ ). Frequency calculations were performed to characterize the stationary points found in the potential energy surfaces. The NMR shielding constants of the $\mathrm{Zn}$ (II) complexes were calculated at the TPSSh/Def2-TZVPP level using the GIAO method. ${ }^{94,95}$ The accuracy of the integration grid was increased by using the integral=superfinegrid keyword. All data are given from Table S7 to S33.

EPR parameters ( $g$ - and A-tensors) were calculated at the TPSSh and BH\&HLYP ${ }^{96,97}$ functionals using the ORCA4 program (release 4.2.1). ${ }^{98,99}$ The $g$-tensors were calculated taking the center of electronic charge as the origin. The resolution of identity (RI-JK) ${ }^{100,101}$ approximation was used to accelerate the convergence of SCF calculations with the aid of the Def $2 / \mathrm{JK}^{102}$ auxiliary basis set. Solvent effects (water) were incorporated with the SMD solvation model. ${ }^{103}$ Spin-orbit effects were considered using the mean-field approach SOMF(1X). ${ }^{104}$

\section{ASSOCIATED CONTENT Supporting Information}

The supporting Information including "X-ray data, ${ }^{1} \mathrm{H}$, ${ }^{13} \mathrm{C}$ NMR (including 2D) and HRMS spectra, atom numbering of compounds, cartesian coordinates of complexes obtained with DFT, calculated pseudocontact shifts" is available.

\section{AUTHOR INFORMATION}

\section{Corresponding Author}

* RT: raphael.tripier@univ-brest.fr

* CPI: cplatas@udc.es

\section{Author Contributions}

The manuscript was written through contributions of all authors. / All authors have given approval to the final version of the manuscript.

\section{Conflict of Interest}

The authors have no conflict of interest to declare ACKNOWLEDGMENT

R. T. and H.B. acknowledge the Ministère de I 'Enseignement Supérieur et de la Recherche and the Centre National de la Recherche Scientifique. They also thank the "Service Commun" of NMR facilities of the University of Brest. R. T., H. B. thank the Brest Metropole for the ARED fellowship of E. L.. C. P.-I. thanks Centro de Supercomputación de Galicia for providing access to computing facilities. M. H. L. acknowledges the National Research Foundation of Korea (NRF) grant funded by the Korean government (NRF-2016R1A5A1009405 and NRF2017R1A2B3002585).

\section{REFERENCES}

(1) Delgado, R.; Félix, V.; Lima, L. M. P.; Price, D. W. Metal Complexes of Cyclen and Cyclam Derivatives Useful for Medical Applications: A Discussion Based on Thermodynamic Stability Constants and Structural Data. Dalton Trans. 2007, 26, 2734-2745.

(2) Wadas, T. J.; Wong, E. H.; Weisman, G. R.; Anderson, C. J. Coordinating Radiometals of Copper, Gallium, Indium, Yttrium, and Zirconium for PET and SPECT Imaging of Disease. Chem. Rev. 2010, 110, 2858-2902.

(3) Liang, X.; Sadler, P. J. Cyclam Complexes and Their Applications in Medicine. Chem. Soc. Rev. 2004, 33, 246-266.

(4) Pugliese, S.; Huan, N. T.; Forte, J.; Grammatico, D.; Zanna, S.; Su, B.; Li, Y.; Fontecave, M. Functionalization of Carbon Nanotubes with Nickel Cyclam for the Electrochemical Reduction of $\mathrm{CO} 2$. ChemSusChem 2020, cssc. 202002092.

(5) Hancock, R. D.; Martell, A. E. Ligand Design for Selective Complexation of Metal Ions in Aqueous Solution. Chem. Rev. 1989, 89, 1875-1914.

(6) Hancock, R. D.; Martell, A. E. The Chelate, Cryptate and Macrocyclic Effects. Comments Inorg. Chem. 1988, 6, 237-284.

(7) Bosnich, B.; Poon, C. K.; Tobe, M. L. Complexes of Cobalt(III) with a Cyclic Tetradentate Secondary Amine. Inorg. Chem. 1965, 4, 1102-1108.

(8) Bailey, M. F.; Curtis, N. F.; Whimp, P. O. Some Cyclic Tetra-Amines and Their Metal-Ion Complexes. Part VI.1 The Crystal Structure of Acetato-C-Rac$(5,7,7,12,14,14$-Hexamethyl- $1,4,8,1 \quad$ I -TetraAzacyclotetradecane)Nickel(II) Perchlorate. J. Chem. Soc. (A) 1970, 1956-1963.

(9) Liang, X.; Weishäupl, M.; Parkinson, J. A.; Parsons, S.; McGregor, P. A.; Sadler, P. J. Selective Recognition of Configurational Substates of Zinc 
Cyclam by Carboxylates: Implications for the Design and Mechanism of Action of Anti-HIV Agents. Chem. Eur. J. 2003, 9 (19), 4709-4717.

(10) Samol'ová, E.; Kuchár, J.; Grzimek, V.; Kliuikov, A.; Čižmár, E. Synthesis, Crystal Structure and Magnetic Properties of the New $\mathrm{Cu}(\mathrm{II}) / \mathrm{Mn}$ (II) Coordination Polymer $\left[\left\{\mathrm{Cu}(\mathrm{Cyclam}) \mathrm{MnCl}_{3}\left(\mathrm{H}_{2} \mathrm{O}\right)_{2}\right\} \mathrm{Cl}\right]$. Polyhedron 2019, 170 , 51-59.

(11) Tasker, P. A.; Sklar, L. Crystal and Molecular Structure of Di(Perchlorato)(1,4,8,11-TetraazacycloTetradecane)Copper (II). Cu(Cyclam) $\left(\mathrm{ClO}_{4}\right)_{2}$. J. Cryst. Mol. Struct. 1975, 5, 329-344.

(12) Tyson, T. A.; Hodgson, K. O.; Hedman, B.; Clark, G. R. Structure of $\mathrm{Zn}(\mathrm{Cyclam})\left(\mathrm{ClO}_{4}\right)_{2}$. Acta Cryst. 1990, C46, 1638-1640.

(13) Ivanikova, R.; Fuess, H.; Mašlejová, A. TransDichloro(1,4,8,11tetraazacyclotetradecane)Cobalt (III) Chloride. Acta Cryst. 2006, E62, m1553-m1554.

(14) Derrick, J. S.; Lee, J.; Lee, S. J. C.; Kim, Y.; Nam, E.; Tak, H.; Kang, J.; Lee, M.; Kim, S. H.; Park, K.; Cho, J.; Lim, M. H. Mechanistic Insights into Tunable MetalMediated Hydrolysis of Amyloid- $\beta$ Peptides. J. Am. Chem. Soc. 2017, 139, 2234-2244.

(15) Lee, T.-J.; Lee, T.-Y.; Hong, C.-Y.; Wu, D.-T.; Chung, C.-S. Structure of Aqua[(1 SR,4 RS,8 SR,11 RS )-1,4,8,11-Tetramethyl-1,4,8,11-

Tetraazacyclotetradecane]Copper(II) Monohydrate. Acta Cryst. 1986, C42, 999-1001.

(16) Lu, T. H.; Shui, W. Z.; Tung, S. F.; Chi, T. Y.; Liao, F. L.; Chung, C. S. (Isothiocyanato-KN)(1,4,8,11Tetramethyl-1,4,8,11-TetraazacyclotetradecaneK4N)Copper(II) Perchlorate. Acta Cryst. 1998, C54, 1071-1072.

(17) Alcock, N. W.; Herron, N.; Moore, P. Comparison of the Structure and Dynamic Properties of Anion (1,4,8,11- Tetramethyl-1 4,8,11 -TetraAzacyclotetradecane)Zinc(II) Perchlorate Complexes in Nitromethane Solutions, and the Crystal and Molecular Structure of the Chloro-Complex. J.C.S Dalton 1978, 1282-1288.

(18) Panneerselvam, K.; Lu, T.-H.; Chi, T.-Y.; Tung, S.-F.; Chung, C.-S. Crystal Structure of Aqua(1,4,8,11Tetramethyl-1,4,8,11-Tetraazacyclotetradecane-

$\mathrm{N}, \mathrm{N}^{\prime}, \mathrm{N}^{\prime \prime}, \mathrm{N}^{\prime \prime \prime}$ Zinc(II) Diperchlorate Monohydrate. Anal. Sci. 1999, 15, 205-206.

(19) Derrick, J. S.; Kim, Y.; Tak, H.; Park, K.; Cho, J.; Kim, S. H.; Lim, M. H. Stereochemistry of Metal Tetramethylcyclam Complexes Directed by an Unexpected Anion Effect. Dalton Trans. 2017, 46, 13166-13170.

(20) Kim, G.; Lelong, E.; Kang, J.; Suh, J.-M.; Le Bris, N.; Bernard, H.; Kim, D.; Tripier, R.; Lim, M. H. Reactivities of Cyclam Derivatives with Metal-AmyloidB. Inorg. Chem. Front. 2020, 7, 4222-4238.

(21) Royal, G.; Dahaoui-Gindrey, V.; Dahaoui, S.; Tabard, A.; Guilard, R.; Pullumbi, P.; Lecomte, C. New Synthesis of Trans-Disubstituted Cyclam Macrocycles Elucidation of the Disubstitution Mechanism on the Basis of X-Ray Data and Molecular Modeling. Eur. J. Org. Chem. 1998, 1971-1975.

(22) Weisman, G. R.; Rogers, M. E.; Wong, E. H.; Jasinski, J. P.; Paight, E. S. Cross-Bridged Cyclam. Protonation and Lithium Cation $\left(\mathrm{Li}^{+}\right)$Complexation in a Diamond-Lattice Cleft. J. Am. Chem. Soc. 1990, 112, 8604-8605.

(23) Weisman, G. R.; Wong, E. H.; Hill, D. C.; Rogers, M. E.; Reed, D. P.; Calabrese, J. C. Synthesis and Transition-Metal Complexes of New Cross-Bridged Tetraamine Ligands. Chem. Commun. 1996, 8, 947948.
(24) Niu, W.; Wong, E. H.; R. Weisman, G.; Lam, K.C.; Rheingold, A. L. Two Novel Zinc(II) Complexes of the 1,8-Cross-Bridged Cyclam Ligand and Their Structures. Inorg. Chem. Comm. 1999, 2, 358-360.

(25) Hubin, T. J.; McCormick, J. M.; Alcock, N. W.; Clase, H. J.; Busch, D. H. Crystallographic Characterization of Stepwise Changes in Ligand Conformations as Their Internal Topology Changes and Two Novel Cross-Bridged Tetraazamacrocyclic Copper(II) Complexes. Inorg. Chem. 1999, 38, 44354446.

(26) Wong, E. H.; Weisman, G. R.; Hill, D. C.; Reed, D. P.; Rogers, M. E.; Condon, J. S.; Fagan, M. A.; Calabrese, J. C.; Lam, K.-C.; Guzei, I. A.; Rheingold, A. L. Synthesis and Characterization of Cross-Bridged Cyclams and Pendant-Armed Derivatives and Structural Studies of their Copper(II) Complexes. J. Am. Chem. Soc. 2000, 122, 10561-10572.

(27) Camus, N.; Halime, Z.; Le Bris, N.; Bernard, H.; Platas-Iglesias, C.; Tripier, R. Full Control of the Regiospecific $N$-Functionalization of $C$-Functionalized Cyclam Bisaminal Derivatives and Application to the Synthesis of Their TETA, TE2A, and CB-TE2A Analogues. J. Org. Chem. 2014, 79, 1885-1899.

(28) Frindel, M.; Le Saëc, P.; Beyler, M.; Navarro, A.S.; Saï-Maurel, C.; Alliot, C.; Chérel, M.; Gestin, J.-F.; Faivre-Chauvet, A.; Tripier, R. Cyclam Telpa for ${ }^{64} \mathrm{Cu}$ PET Imaging. Bioconjugation to Antibody, Radiolabeling and Preclinical Application in Xenografted Colorectal Cancer. RSC Adv. 2017, 7, 9272-9283.

(29) Lewis, E. A.; Allan, C. C.; Boyle, R. W.; Archibald, S. J. Efficient $\mathrm{N}$ - and C-Functionalisation of Cyclam Macrocycles utilising Bisaminal Methodology. Tet. Lett. 2004, 45, 3059-3062.

(30) Camus, N.; Halime, Z.; le Bris, N.; Bernard, H.; Beyler, M.; Platas-Iglesias, C.; Tripier, R. A [Two-Step/One Week] Synthesis of C-Functionalized Homocyclens and Cyclams. Application to the Preparation of Conjugable BCAs without Chelating Properties Alteration. RSC Adv. 2015, 5, 85898-85910.

(31) Camus, N.; Le Bris, N.; Nuryyeva, S.; Chessé, M.; Esteban-Gómez, D.; Platas-Iglesias, C.; Tripier, R.; Elhabiri, M. Tuning the Copper(II) Coordination Properties of Cyclam by Subtle Chemical Modifications. Dalton Trans. 2017, 46, 11479-11490.

(32) Le Bihan, T.; Navarro, A.-S.; Le Bris, N.; Le Saëc, P.; Gouard, S.; Haddad, F.; Gestin, J.-F.; Chérel, M.; Faivre-Chauvet, A.; Tripier, R. Synthesis of CFunctionalized TE1PA and Comparison with its Analogues. An Example of Bioconjugation on 9E7.4 MAb for Multiple Myeloma 64Cu-PET Imaging. Org. Biomol. Chem. 2018, 16, 4261-4271.

(33) Halime, Z.; Frindel, M.; Camus, N.; Orain, P.-Y.; Lacombe, M.; Chérel, M.; Gestin, J.-F.; Faivre-Chauvet, A.; Tripier, R. New Synthesis of Phenyl-Isothiocyanate C-functionalised Cyclams. Bioconjugation and ${ }^{64} \mathrm{Cu}$ Phenotypic PET Imaging Studies of Multiple Myeloma with the TE2A Derivative. Org. Biomol. Chem. 2015, 13, 11302-11314.

(34) Felten, A.-S.; Petry, N.; Henry, B.; PellegriniMoïse, N.; Selmeczi, K. C-Functionalized Chiral Dioxocyclam and Cyclam Derivatives with 1,2,3Triazole Units: Synthesis, Complexation Properties and Crystal Structures of Copper II. New J. Chem. 2016, 40, 1507-1520.

(35) Cook, T. D.; Tyler, S. F.; McGuire, C. M.; Zeller, M.; Fanwick, P. E.; Evans, D. H.; Peters, D. G.; Ren, T. Nickel Complexes of C-Substituted Cyclams and Their Activity for $\mathrm{CO}_{2}$ and $\mathrm{H}^{+}$Reduction. ACS Omega 2017, 2, 3966-3976. 
(36) Tabushi, I.; Kato, H. Preparation of C-Alkylated Macrocyclic Polyamines. Tet. Lett. 1977, 12, 10491052.

(37) Kou, F.; Zhu, S.; Lin, H.; Chen, W.; Chen, Y.; Lin, $M$. Kinetics and Mechanism of the Acid Dissociation of Copper(II) Complex of Novel C-Functionalized Macrocylcic Dioxotetramines. Polyhedron 1997, 16, 2021-2028.

(38) Bernhardt, P. V.; Byriel, K. A.; Kennard, C. H. L.; Sharpe, P. C. The Potentially Hexadentate Isomeric Macrocycles Trans- and Cis- 6,13-Diethyl-1,4,8,11Tetraazacyclotetradecane-6,13-Diamine and their Cobalt(III) Complexes: Unexpected Conformational Behavior. Inorg. Chem. 1996, 35, 2045-2052.

(39) Benabdallah, T.; Guglielmetti, R. Une synthèse générale des tétraazamacrocycles mono- $C$ fonctionnalisés. Hel. Chem. Act. 1988, 71, 602-608.

(40) Grenier, L.; Beyler, M.; Platas-Iglesias, C.; Closson, T.; Gómez, D. E.; Seferos, D. S.; Liu, P.; Ornatsky, O. I.; Baranov, V.; Tripier, R. Highly Stable and Inert Complexation of Indium(III) by Reinforced Cyclam Dipicolinate and a Bifunctional Derivative for Bead Encoding in Mass Cytometry. Chem. Eur. J. 2019, 25, 15387-15400.

(41) Micheloni, M.; Paoletti, P. The macrocyclic effect: Thermodynamic parameters for the formation of zinc(II) complexes with macrocyclic ligands of varying ring-size. Inorg. Chim. Acta 1980, 43, 109-112.

(42) Beattie, J. K. Conformational Analysis of Tris(ethylenediamine) Complexes. Acc. Chem Res. 1971, 4, 253-259.

(43) Niu, W.; Wong, E. H.; Weisman, G. R.; Hill, D. C.; Tranchemontagne, D. J.; Lam, K.-C.; Sommer, R. D.; Zakharov, L. N.; Rheingold, A. L. Inside or Outside a Ligand Cleft? Synthetic, Structural, and Kinetic Inertness Studies of Zinc, Cadmium, and Mercury Complexes of Crossbridged Cyclam and Cyclen. Dalton Trans. 2004, 3536-3547.

(44) Otte, D. A. L.; Borchmann, D. E.; Lin, C.; Weck, M.; Woerpel, K. A. ${ }^{13} \mathrm{C}$ NMR Spectroscopy for the Quantitative Determination of Compound Ratios and Polymer End Groups. Org. Lett. 2014, 16, 1566-1569.

(45) Hathaway, B. J. Copper. Coord. Chem. Rev. 1983, 52, 87-169.

(46) Hathaway, B. J.; Tomlinson, A. A. G. Copper(II) Ammonia Complexes. Coord. Chem. Rev. 1970, 5, 143.

(47) Hathaway, B. J.; Billing, D. E. The Electronic Properties and Stereochemistry of Mono-Nuclear Complexes of the Copper(II) Ion. Coord. Chem. Rev. 1970, 5, 143-207.

(48) Lever, A. B. P. Inorganic Electronic Spectroscopy, $2^{\text {nd }}$ Ed; Elsevier: Amsterdam, 1984; 554572.

(49) Hendrich, M. P. SpinCount Software; Carnegie Mellon University, available at http://www.chem.cmu.edu/groups/hendrich/.

(50) Billing, D. E.; Hathaway, B. J.; Nicholls, P. Polarisations of the Copper(II) and Uranyl Electronic Spectra of Meta-Zeunerite Single Crystals. J. Chem. Soc., A 1969, 316-319.

(51) Li, Y. X-Ray Structures and Spectroscopic Studies of Diaqua- and Dichlorocopper(II) Complexes of 15-Crown-5 and 4'-Substituted Benzo-15-Crown-5 with a $3 \mathrm{~d}_{\mathrm{z}}{ }^{2}$ Ground-State Doublet. Bull. Chem. Soc. Jpn. 1996, 69, 2513-2523.

(52) Valko, M.; Morris, H.; Mazúr, M.; Telser, J.; Mclnnes, E. J. L.; Mabbs, F. E. High-Affinity Binding Site for Copper(II) in Human and Dog Serum Albumins (an EPR Study). J. Phys. Chem. B 1999, 103, 5591-5597.
(53) Lommens, P.; Feys, J.; Vrielinck, H.; De Buysser, K.; Herman, G.; Callens, F.; Van Driessche, I. EPR and Speciation Simulation Study of $\mathrm{Cu}^{2+}$ Complexes in an Amine-Based Aqueous Precursor System Used for Preparation of Superconducting YBCO Coatings. Dalton Trans. 2012, 41, 3574.

(54) Rakhit, G.; Sarkar, B. Electron Spin Resonance Study of the Copper(II) Complexes of Human and Dog Serum Albumins and Some Peptide Analogs. Journal of Inorganic Biochemistry 1981, 15, 233-241.

(55) Esteves, C. V.; Lamosa, P.; Delgado, R.; Costa, J.; Désogère, P.; Rousselin, Y.; Goze, C.; Denat, F. Remarkable Inertness of Copper(II) Chelates of CyclenBased Macrobicycles with Two Trans- N-Acetate Arms. Inorg. Chem. 2013, 52, 5138-5153.

(56) Fabbrizzi, L.; Montagna, L.; Poggi, A.; Kaden, T. A.; Siegfried, L. C. Bicyclam $\left[6,6^{\prime}-\mathrm{Bi}(1,4,8,1]\right.$-tetraAzacyclotetradecane)]: A Ditopic Receptor for Homoand Hetero-Bimetallic Complexes. J. Chem. Soc., Dalton Trans. 1987, 11, 2631-2634.

(57) Addison, A. W.; Sinn, E. A Stable Bis(Thiolate) of Copper(II) with Long Axial Copper-Sulfur Linkages: Crystal and Molecular Structure of Trans-[Cu(Cyclam) (SC6F5)2]. Inorg. Chem. 1983, 22, 1225-1228.

(58) Lachkar, M.; Guilard, R.; Atmani, A.; De Cian, A.; Fischer, J.; Weiss, R. Synthesis of New Binucleating Cylindrical Macrotricyclic Ligands Where Two Cyclam Rings Are in a Face-to-Face Conformation. Characterization of Their Dicopper(II) and Dinickel(II) Complexes. Inorg. Chem. 1998, 37, 1575-1584.

(59) Dong, Y.; Lawrance, G. A.; Lindoy, L. F.; Turner, $P$. Macrocyclic Ligand Design. Interaction of a Series of Successively N-Benzylated Derivatives of 1,4,8,11Tetraazacyclotetradecane (Cyclam) with Copper(II) and Nickel(II). Dalton Trans. 2003, 8, 1567-1576.

(60) Sakaguchi, U.; Addison, A. W. Spectroscopic and Redox Studies of Some Copper(II) Complexes with Biomimetic Donor Atoms: Implications for Protein Copper Centres. J. Chem. Soc., Dalton Trans. 1979, 4, 600-608.

(61) Yokoi, H.; Sai, M.; Isobe, T.; Ohsawa, S. ESR Studies of the Copper(II) Complexes of Ammo Acids. Bull. Chem. Soc. Jpn. 1972, 45, 2189-2195.

(62) Lau, P. W.; Lin, W. C. Electron Spin Resonance and Electronic Structure of Some Metalloporphyrins. J. Inorg. Nucl. Chem. 1975, 37, 2389-2398.

(63) Barbaro, P.; Bianchini, C.; Capannesi, G.; Di Luca, L.; Laschi, F.; Petroni, D.; Salvadori, P. A.; Vacca, A.; Vizza, F. Synthesis and Characterization of the Tetraazamacrocycle 4,10-Dimethyl-1,4,7,10Tetraazacyclododecane-1,7-Diacetic Acid $\left(\mathrm{H}_{2} \mathrm{Me}_{2} \mathrm{DO}_{2} \mathrm{~A}\right)$ and of Its Neutral Copper(II) Complex [Cu( $\left.\left.\mathrm{Me}_{2} \mathrm{DO}_{2} \mathrm{~A}\right)\right]$. A New ${ }^{64} \mathrm{Cu}$-Labeled Macrocyclic Complex for Positron Emission Tomography Imaging. J. Chem. Soc., Dalton Trans. 2000, 14, 2393-2401.

(64) Guerra, K. P.; Delgado, R.; Lima, L. M. P.; Drew, M. G. B.; Félix, V. Bis- and Tris-(Methylphosphonic) Acid Derivatives of a 14-Membered Tetraazamacrocycle Containing Pyridine: Synthesis, Protonation and Complexation Studies. Dalton Trans. 2004, 12, 18121822.

(65) Félix, V.; Delgado, R.; Amorim, M. T. S.; Chaves, S.; Galvão, A. M.; Duarte, M. T.; de C. T. Carrondo, M. A. A. F.; Moura, I.; da Silva, J. J. R. F. Electron Spin Resonance Studies and Crystal Structures of Copper(II) Complexes of some 12-, 13- and 14Membered Oxatriaza Macrocycles. J. Chem. Soc., Dalton Trans. 1994, 21, 3099-3106.

(66) Studer, M.; Riesen, A.; Kaden, T. A. Metal Complexes with Macrocyclic Ligands Part XXX. Synthesis and structure of halocuprates of 
tetraprotonated 1,4,8,11-tetraazacyclotetradecane and its $\mathrm{Cu}^{2+}$ complex. Helv. Chim. Acta 1989, 72, 12531258.

(67) Chen, X.; Long, G.; Willett, R. D.; Hawks, T.; Molnar, S.; Brewer, K. Three Metal (1,4,8,11Tetraazacyclotetradecane) Halide Salts. Acta Cryst. C Cryst Struct Commun 1996, 52, 1924-1928.

(68) Lima, L. M. P.; Esteban-Gómez, D.; Delgado, R.; Platas-Iglesias, C.; Tripier, R. Monopicolinate Cyclen and Cyclam Derivatives for Stable Copper(II) Complexation. Inorg. Chem. 2012, 51, 6916-6927.

(69) Rodríguez-Rodríguez, A.; Halime, Z.; Lima, L. M. P.; Beyler, M.; Deniaud, D.; Le Poul, N.; Delgado, R.; Platas-Iglesias, C.; Patinec, V.; Tripier, R. Cyclams with Ambidentate Methylthiazolyl Pendants for Stable, Inert, and Selective $\mathrm{Cu}(\mathrm{II})$ Coordination. Inorg. Chem. 2016, 55, 619-632.

(70) Maimon, E.; Zilbermann, I.; Golub, G.; Ellern, A.; Shames, A. I.; Cohen, H.; Meyerstein, D. Comproportionation and Redox Catalyzed Isomerization of $\mathrm{Cu}(\mathrm{II})(1 \mathrm{R}, 4 \mathrm{~S}, 8 \mathrm{R}, 11 \mathrm{~S}-1,4,8,11$-Tetramethyl-1,4,8,11-

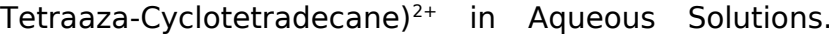
Inorg. Chim. Acta 2001, 324, 65-72.

(71) Sciortino, G.; Lubinu, G.; Maréchal, J.-D.; Garribba, E. DFT Protocol for EPR Prediction of Paramagnetic $\mathrm{Cu}(\mathrm{II})$ Complexes and Application to Protein Binding Sites. Magnetochemistry 2018, 4, 55

(72) Solomon, E. I.; Hare, J. W.; Dooley, D. M.; Dawson, J. H.; Stephens, P. J.; Gray, H. B. Spectroscopic Studies of Stellacyanin, Plastocyanin, and Azurin. Electronic Structure of the Blue Copper Sites. J. Am. Chem. Soc. 1980, 102, 168-178.

(73) Bertini, I.; Canti, G.; Grassi, R.; Scozzafava, A. Effects of Planar and Tetrahedral Distortions on the ESR Parameters of Bis(Salicylaldiminato)Copper(II) Complexes. Inorg. Chem. 1980, 19, 2198-2200.

(74) Solomon, E. I.; Penfield, K. W.; Wilcox, D. E. Active Sites in Copper Proteins an Electronic Structure Overview. In Copper, Molybdenum, and Vanadium in Biological Systems; Structure and Bonding. vol 53. Springer, Berlin, Heidelberg. 1983, 1-57.

(75) Garribba, E.; Micera, G. The Determination of the Geometry of Cu(II) Complexes: An EPR Spectroscopy Experiment. J. Chem. Educ. 2006, 83, 1229.

(76) Halcrow, M. A. Interpreting and Controlling the Structures of Six-Coordinate Copper (II) Centres - When Is a Compression Really a Compression? Dalton Trans. 2003, 23, 4375-4384.

(77) Lima, L. M. P.; Halime, Z.; Marion, R.; Camus, N.; Delgado, R.; Platas-Iglesias, C.; Tripier, R. Monopicolinate Cross-Bridged Cyclam Combining Very Fast Complexation with Very High Stability and Inertness of Its Copper(II) Complex. Inorg. Chem. 2014, 53, 5269-5279.

(78) Paúrová, M.; David, T.; Císařová, I.; Lubal, P.; Hermann, P.; Kotek, J. Optimization of the Selectivity and Rate of Copper Radioisotope Complexation: Formation and Dissociation Kinetic Studies of 1,4,8Trimethylcyclam-Based Ligands with Different Coordinating Pendant Arms. New J. Chem. 2018, 42, 11908-11929.

(79) Woodin, K. S.; Heroux, K. J.; Boswell, C. A.; Wong, E. H.; Weisman, G. R.; Niu, W.; Tomellini, S. A.; Anderson, C. J.; Zakharov, L. N.; Rheingold, A. L. Kinetic Inertness and Electrochemical Behavior of Copper(II) Tetraazamacrocyclic Complexes: Possible Implications for in Vivo Stability. Eur. J. Inorg. Chem. 2005, 48294833.

(80) Bucher, C.; Duval, E.; Espinosa, E.; Barbe, J.-M.; Verpeaux, J.-N.; Amatore, C.; Guilard, R. First Direct
Synthesis of a Trans-III Complex of Tetramethylcyclam - Physicochemical Characterization, Electrochemistry and X-ray Crystal Structure of 1,4,8,11-Tetramethyl1,4,8,11-tetraazacyclotetradecane Copper(II) Bistetrafluoroborate. Eur. J. Inorg. Chem. 2001, 10771079.

(81) Bucher, C.; Duval, E.; Barbe, J.-M.; Verpeaux, J.N.; Amatore, C.; Guilard, R. Synthesis, Characterization and X-Ray Crystal Structure of Cyclam Derivatives. Part III. Formation and Electrochemically Induced Isomerization of Copper Complexes of 1,8 -Bis $(\mathrm{N}, \mathrm{N}$ Dimethylcarbamoylmethyl)-4,11-Dimethyl-1,4,8,11Tetraazacyclotetradecane. C. R. Acad. Sci. Paris - Series IIC - Chemistry 2000, 3, 211-222.

(82) Bucher, C.; Moutet, J.-C.; Pécaut, J.; Royal, G.; Saint-Aman, E.; Thomas, F. Redox-Triggered Molecular Movement in a Multicomponent Metal Complex in Solution and in the Solid State. Inorg. Chem. 2004, 43, 3777-3779.

(83) Bucher, C.; Moutet, J.-C.; Pécaut, J.; Royal, G.; Saint-Aman, E.; Thomas, F.; Torelli, S.; Ungureanu, M. Thermically and Electrochemically Induced Isomerization of a (Bis(Ferrocene)-cyclam)Copper(II) Complex. Inorg. Chem. 2003, 42, 2242-2252.

(84) Grujicic, D.; Pesic, B. Electrodeposition of Copper: The Nucleation Mechanisms. Electrochimica Acta 2002, 47, 2901-2912.

(85) Désogère, P.; Rousselin, Y.; Poty, S.; Bernhard, C.; Goze, C.; Boschetti, F.; Denat, F. Efficient Synthesis of 1,4,7-Triazacyclononane and 1,4,7Triazacyclononane-Based Bifunctional Chelators for Bioconjugation: Triazacyclononane-Based Bifunctional Chelators. Eur. J. Org. Chem. 2014, 2014, 7831-7838.

(86) Cakić, N.; Gündüz, S.; Rengarasu, R.; Angelovski, G. Synthetic Strategies for Preparation of Cyclen-Based MRI Contrast Agents. Tetrahedron Lett. 2015, 56, 759-765.

(87) CrysAlis Software System, Version 1.171.28 Cycle 4 Beta; Oxford Diffraction Ltd.: Abingdon, U.K., 2005

(88) Sheldrick, G. M. A Short History of SHELX. 2008, A64, 112-122.

(89) Frisch, M. J.; Trucks, G. W.; Schlegel, H. B.; Scuseria, G. E.; Robb, M. A.; Cheeseman, J. R.; Scalmani, G.; Barone, V.; Petersson, G. A.; Nakatsuji, H.; Li, X.; Caricato, M.; Marenich, A. V.; Bloino, J.; Janesko, B. G.; Gomperts, R.; Mennucci, B.; Hratchian, H. P.; Ortiz, J. V.; Izmaylov, A. F.; Sonnenberg, J. L.; WilliamsYoung, D.; Ding, F.; Lipparini, F.; Egidi, F.; Goings, J.; Peng, B.; Petrone, A.; Henderson, T.; Ranasinghe, D.; Zakrzewski, V. G.; Gao, J.; Rega, N.; Zheng, G.; Liang, W.; Hada, M.; Ehara, M.; Toyota, K.; Fukuda, R.; Hasegawa, J.; Ishida, M.; Nakajima, T.; Honda, Y.; Kitao, O.; Nakai, H.; Vreven, T.; Throssell, K.; Montgomery, J. A., Jr.; Peralta, J. E.; Ogliaro, F.; Bearpark, M. J.; Heyd, J. J.; Brothers, E. N.; Kudin, K. N.; Staroverov, V. N.; Keith, T. A.; Kobayashi, R.; Normand, J.; Raghavachari, K.; Rendell, A. P.; Burant, J. C.; lyengar, S. S.; Tomasi, J.; Cossi, M.; Millam, J. M.; Klene, M.; Adamo, C.; Cammi, R.; Ochterski, J. W.; Martin, R. L.; Morokuma, K.; Farkas, O.; Foresman, J. B.; Fox, D. J. Gaussian 16, revision BC.01; Gaussian, Inc.: Wallingford, CT, 2016.

(90) Tao, J.; Perdew, J. P.; Staroverov, V. N.; Scuseria, G. E. Climbing the Density Functional Ladder: Nonempirical Meta-Generalized Gradient Approximation Designed for Molecules and Solids. Phys. Rev. Lett. 2003, 91, 146401.

(91) Weigend, F.; Ahlrichs, R. Balanced Basis Sets of Split Valence, Triple Zeta Valence and Quadruple Zeta Valence Quality for $\mathrm{H}$ to Rn: Design and Assessment of Accuracy. Phys. Chem. Chem. Phys. 2005, 7, 3297. 
(92) Tomasi, J.; Mennucci, B.; Cammi, R. Quantum Mechanical Continuum Solvation Models. Chem. Rev. 2005, 105, 2999-3094.

(93) Rappe, A. K.; Casewit, C. J.; Colwell, K. S.; Goddard, W. A.; Skiff, W. M. UFF, a Full Periodic Table Force Field for Molecular Mechanics and Molecular Dynamics Simulations. J. Am. Chem. Soc. 1992, 114 10024-10035.

(94) Ditchfield, R. Molecular Orbital Theory of Magnetic Shielding and Magnetic Susceptibility. J. Chem. Phys. 1972, 56, 5688-5691.

(95) Helgaker, T.; Jaszuński, M.; Ruud, K. Ab Initio Methods for the Calculation of NMR Shielding and Indirect Spin-Spin Coupling Constants. Chem. Rev. 1999, 99, 293-352.

(96) Becke, A. D. A New Mixing of Hartree-Fock and Local Density-functional Theories. J. Chem. Phys. 1993, 98, 1372-1377.

(97) Lee, C.; Yang, W.; Parr, R. G. Development of the Colle-Salvetti Correlation-Energy Formula into a Functional of the Electron Density. Phys. Rev. B 1988 , 37, 785-789.

(98) Neese, F. The ORCA Program System. WIRES Comput. Mol. Sci. 2012, 2, 73-78.
(99) Neese, F. Software Update: The ORCA Program System, Version 4.0. WIREs Comput. Mol. Sci. 2018, 8.

(100) Kossmann, S.; Neese, F. Comparison of Two Efficient Approximate Hartee-Fock Approaches. Chem. Phys. Lett. 2009, 481, 240-243.

(101) Weigend, F.; Kattannek, M.; Ahlrichs, R. Approximated Electron Repulsion Integrals: Cholesky Decomposition versus Resolution of the Identity Methods. J. Chem. Phys. 2009, 130, 164106.

(102) Weigend, F. Hartree-Fock Exchange Fitting Basis Sets for $\mathrm{H}$ to Rn. J. Comput. Chem. 2008, 29 167-175.

(103) Marenich, A. V.; Cramer, C. J.; Truhlar, D. G. Universal Solvation Model Based on Solute Electron Density and on a Continuum Model of the Solvent Defined by the Bulk Dielectric Constant and Atomic Surface Tensions. J. Phys. Chem. B 2009, 113, 63786396.

(104) Neese, F. Efficient and Accurate Approximations to the Molecular Spin-Orbit Coupling Operator and Their Use in Molecular g-Tensor Calculations. J. Chem. Phys. 2005, 122, 034107. 


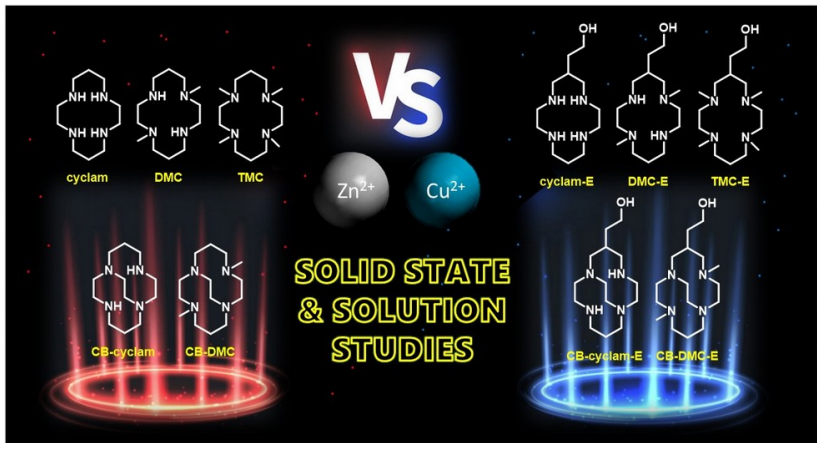

We present a complete comparative study of the coordination properties toward $\mathrm{Cu}$ (II) and $\mathrm{Zn}$ (II) of $C$-functionalized cyclam derivatives (bearing an additional hydroxyethyl group) and their parent cyclam analogues, with especial attention to the various isomers formed in solution and in the solid state. 